\title{
Quality of Life and Health Status Among Patients Receiving Renal Replacement Therapy in Trinidad and Tobago, West Indies
}

\author{
Sharlene Sanchez (D) \\ Surujpal Teelucksingh ${ }^{2}$ \\ Ronan Ali $\mathbb{D}^{2}$ \\ Henry Bailey (D) $^{3}$ \\ George Legall ${ }^{4}$ \\ 'Department of Medicine, North Central \\ Regional Health Authority, Arima \\ General Hospital, Arima, Trinidad and \\ Tobago, West Indies; ${ }^{2}$ Department of \\ Clinical Medical Sciences, University of \\ the West Indies, St. Augustine, Trinidad \\ and Tobago, West Indies; ${ }^{3}$ Department of \\ Economics, University of the West Indies, \\ St Augustine, Trinidad and Tobago, West \\ Indies; ${ }^{4}$ Department of Natural Sciences, \\ University of the West Indies, St \\ Augustine, Trinidad and Tobago, West \\ Indies
}

Correspondence: Sharlene Sanchez Arima General Hospital, Queen Mary Avenue, Arima, Trinidad and Tobago, West Indies

Tel +I-868-46I-5724

Email sanchezsharlene32@yahoo.com
Purpose: The determinants of quality of life for patients on renal replacement therapy vary across the world. The aim of this study is to determine the quality of life of patients on renal replacement therapy in Trinidad and Tobago and predictors thereof.

Patients and Methods: This cross-sectional study took place over a 1-year period. Data were obtained from 530 out of 1383 patients meeting inclusion criteria (100 transplants, 80 peritoneal dialyses, 350 hemodialyses) using the survey instruments. Stratified random sampling with proportional allocation was used to select patients at hemodialysis centres. The Kidney Disease Quality of Life questionnaire (KDQOL-36), EuroQol and demographic questionnaires were administered via face-to-face interviews. SPSS24, STATA14 and MINITAB18 were used for descriptive and inferential data analysis.

Results: Of the 530 patients, $52.5 \%$ were male, $37.5 \%$ were in the $56-65$ years age group and $51.3 \%$ were of Indo-Trinbagonian descent. Hypertension $(25.5 \%)$ and type 2 diabetes mellitus $(62.0 \%)$ were reported as the main causes of kidney disease in the dialysis group. In the transplant category, chronic glomerulonephritis (45\%) was the main aetiology of kidney disease. The KDQOL-36 domain scores and significantly associated variables included modality of renal replacement, Charlson's Comorbidity Index, ethnicity, income and employment status. Transplant patients had higher mean subcomponent Kidney Disease Quality of Life scores and performed better in the EuroQol than patients on dialysis. Patients on peritoneal dialysis had a better quality of life than hemodialysis patients. Among patients on hemodialysis, an arteriovenous fistula significantly impacted their quality of life.

Conclusion: Renal transplant recipients enjoy the best quality of life and health state among patients on renal replacement therapy in Trinidad and Tobago. Increasing patients' access to renal transplantation or peritoneal dialysis will markedly improve health status for the number of years of renal replacement therapy.

Keywords: renal transplant, peritoneal dialysis, hemodialysis, EuroQol, Kidney Disease Quality of Life questionnaire

\section{Plain Language Summary}

We study the quality of life of patients receiving hemodialysis, peritoneal dialysis and those with renal transplants on the twin islands of Trinidad and Tobago. Approximately half of the patients are of Indo-Trinbagonian origin. Almost two-thirds of persons have type 2 diabetes mellitus in the dialysis group. Data using quality-of-life questionnaires from 530 patients (100 renal transplants, 80 peritoneal dialyses, 350 hemodialyses) show that renal transplant patients have the best quality of life. Patients on peritoneal dialysis also have a good quality of life. Among patients on hemodialysis, those with an arteriovenous fistula/graft performed 
better in the questionnaires than those with permanent catheters. Allowing patients greater access to these resources for renal replacement therapy will impact immensely on health status. This study is the first in the Caribbean to assess the quality of life of patients on therapies for end-stage renal disease. The findings can influence future decision and policy making in Latin America, the Caribbean and low-income countries.

\section{Introduction}

The measurement of quality of life in patients with chronic disease is a complex entity that encompasses state of health, impact of disease, emotional factors and social support. Chronic kidney disease with its associated comorbidities and complications is a great challenge for physicians, patients and caregivers. Renal replacement therapy for end-stage renal disease includes hemodialysis, peritoneal dialysis and renal transplantation. Patients with an improved quality of life have better treatment outcomes and decreased morbidity and mortality. ${ }^{1-6}$ This study is the first in the Caribbean to evaluate the quality of life and health state associated with renal replacement therapy. In other settings, the determinants of quality of life of patients on renal replacement therapy are different. ${ }^{7-15}$ This study will provide West Indian data in a developing country that can be used for policy determination in the Caribbean and low resource populations across the globe.

An earlier small study in Trinidad had shown that $18 \%$ of asymptomatic patients had evidence for stage 3 chronic kidney disease. ${ }^{16}$ Data from the Caribbean showed that diabetes and hypertension were the major contributors to this burden. ${ }^{17}$ Of the modalities of renal replacement, renal transplantations offer the best survival, with survival rates in Trinidad of 91.46\% (Standard Error 0.04), 89.51\% (Standard Error 0.04) and 86.31\% (Standard Error 0.05) for 1 year, 2 years and 3 years, respectively. ${ }^{18}$ However, the decision and choice of modality of renal replacement therapy are influenced by multiple factors. In Trinidad and Tobago, government funding for hemodialysis is dependent on a patient's present economic circumstances, which is assessed by the state. On the other hand, peritoneal dialysis is offered to all patients once they are deemed suitable for this therapy. The attending nephrologist determines referrals to the renal transplantation unit and criteria must be fulfilled to be considered for transplantation.

The aim of this study is to investigate patients on renal replacement therapy with a good quality of life to allocate resources in the future and to identify factors attributing to a better quality of life and health status. Findings will also aid physicians in guiding choices of therapy tailored to individual circumstances and educate patients in their decision-making when considering the modality of renal replacement therapy.

\section{Patients and Methods}

\section{Study Description}

The study was a cross-sectional study, the target population being all adult patients on all forms of renal replacement therapy in Trinidad and Tobago. The survey period ran for just over 1 year from the 1st October 2015 to the 31st October 2016. Quality of life and health status were measured with established questionnaires and factors contributing to a high quality of life were determined.

Patients receiving renal replacement therapy in Trinidad and Tobago start dialysis or receive a renal transplant. Dialysis options include peritoneal dialysis and hemodialysis. The government of Trinidad and Tobago funds this service. Hemodialysis and peritoneal dialysis are offered at the public health facilities with no user fees. Due to insufficient public facilities to cater for the number of patients requiring hemodialysis, the Ministry of Health through an external patient programme funds most patients that qualify (based on patient's socioeconomic status) at privately operated hemodialysis centres. Overall, whether a patient obtains this treatment in a public or private hemodialysis centre, the government ultimately provides this service for the vast majority. Potential transplant recipients access the central totally government-funded transplant unit via referrals from specialist nephrologists and such candidates are considered for living or deceased donor transplants.

\section{Inclusion and Exclusion Criteria}

The inclusion criteria were being a kidney transplant recipient or receiving dialysis for 3 months or more and being at least 18 years of age. Studies have shown that this period is essential for adaptation to activities of daily living and return to regular functioning. ${ }^{6,9,10}$

The exclusion criteria were being on renal replacement therapy for less than 3 months and being less than 18 years of age. Furthermore, persons hospitalized within 4 weeks from administration of the questionnaires were excluded from this study in keeping with the recommendation of the developers of the Kidney Disease Quality of Life instrument. 


\section{Sample Size}

Since there are no formulas or tables for determining or choosing sample sizes for non-random samples, the formula for computing sample sizes for simple random samples with replacement from finite populations was used to determine the number of participants that would be needed for the study.

A total of $\mathrm{N}=1383$ patients (Transplant: 112, Peritoneal Dialysis: 87, Haemodialysis: 1184) satisfied the inclusion criteria. Of the 1383 patients, it was determined that a sample of size $n=546$ was the smallest number of patients needed for survey purposes and for estimating quality of life quantitatively, with a $5 \%$ margin of error. Data were collected for approximately 1 year from the 1st October 2015 to the 31st October 2016. There is one transplantation centre in Trinidad and Tobago. Renal transplant recipients participated from this centre. There are 3 hospitals, all in the public setting in Trinidad and Tobago, that offer peritoneal dialysis and 5 hospitals in the public sector offering haemodialysis. Patients on dialysis participated from these facilities. Stratified random sampling with proportional allocation by regional health authority was used to determine the participants from the respective private haemodialysis centres (Figure 1). Geographical locations using distributions within health authorities were used to obtain ratios for stratified random sampling. The allocations in the North Central, North West, and South West regional authorities were in the ratio 1:1:2. Eight of the 16 private hemodialysis centres were surveyed. There were no private centres during the time of this study within the Eastern Regional Health Authority and Tobago Regional Health Authority.

\section{Questionnaires}

The International Standard Classification of Occupations of the United Nations, ${ }^{19}$ the World Health Organization Global Database on Body Mass Index ${ }^{20}$ and the International Statistical Classification of Diseases and Related Health Problems 10th Revision ${ }^{21}$ were used to classify occupation, body mass index and diseases, respectively, in the demographics questionnaire. The demographics questionnaire also included information from participants on age, gender, ethnicity, comorbidities, aetiology of kidney disease, mode of renal replacement therapy, access type for hemodialysis, income bracket, employment status, smoking and alcohol consumption.
For the obese category, persons of Asian $\left(25 \mathrm{~kg} / \mathrm{m}^{2}\right)$ and Afro-Caribbean descents $\left(27 \mathrm{~kg} / \mathrm{m}^{2}\right)$ were classified based on a prospective study that investigated ethnic groups. ${ }^{22}$ Charlson's Comorbidity Index estimates 10-year survival in patients with multiple comorbidities. ${ }^{23}$ A higher score indicates a lower percentage estimated 10-year survival. Charlson's comorbidity index and mean quality of life scores were calculated.

The Kidney Disease Quality of Life questionnaire is a 36-item questionnaire that investigates quality of life. This was developed for patients with chronic renal disease and dialysis patients. It has been used for the evaluation of transplant patients and is valid and reliable in many populations. ${ }^{24-28}$ The domain components include a physical component score (PCS), mental component score (MCS) symptoms and problems of kidney disease (SPKD), burden of kidney disease (BKD) and effect of kidney disease (EKD). All Kidney Disease Quality of Life items were on a varying Likert scale.

The EuroQol self-reported health instrument was included. The EuroQol classification system has five domains: mobility, self-care, ability to perform usual activities, pain/discomfort and anxiety/depression. Each dimension is scored from 1 to 3 with 1 representing "no problems", 2 representing "moderate problems", and 3 representing "extreme problems". The EuroQol selfreported health instrument also includes a visual analogue scale on which a respondent provides their selfassessed health rating from 0 (worst health imaginable) to 100 (best health imaginable). The EuroQol value set for Trinidad and Tobago was used to determine utility values for patients on all modalities of renal replacement therapy. ${ }^{29}$ Trinidad and Tobago EuroQol population norms from a forthcoming study were used to compare EuroQol results for the patients on renal replacement therapy.

\section{Data Collection and Informed Consent}

Preparation for fieldwork included piloting and editing the questionnaire, creating a field manual to guide for the data collection process and a coding dictionary to facilitate data to be used for data coding (qualitative data) prior to data entry. Specific recommendations by the developers of all questionnaires were strictly followed. Prospective data collectors were trained in the use of the field manual. The data were regularly tested for high inter-collector reliability (Cohen's kappa) and 


\section{Tobago}

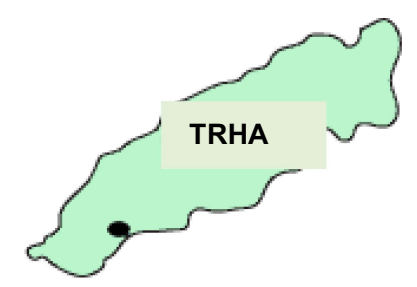

\section{Trinidad}

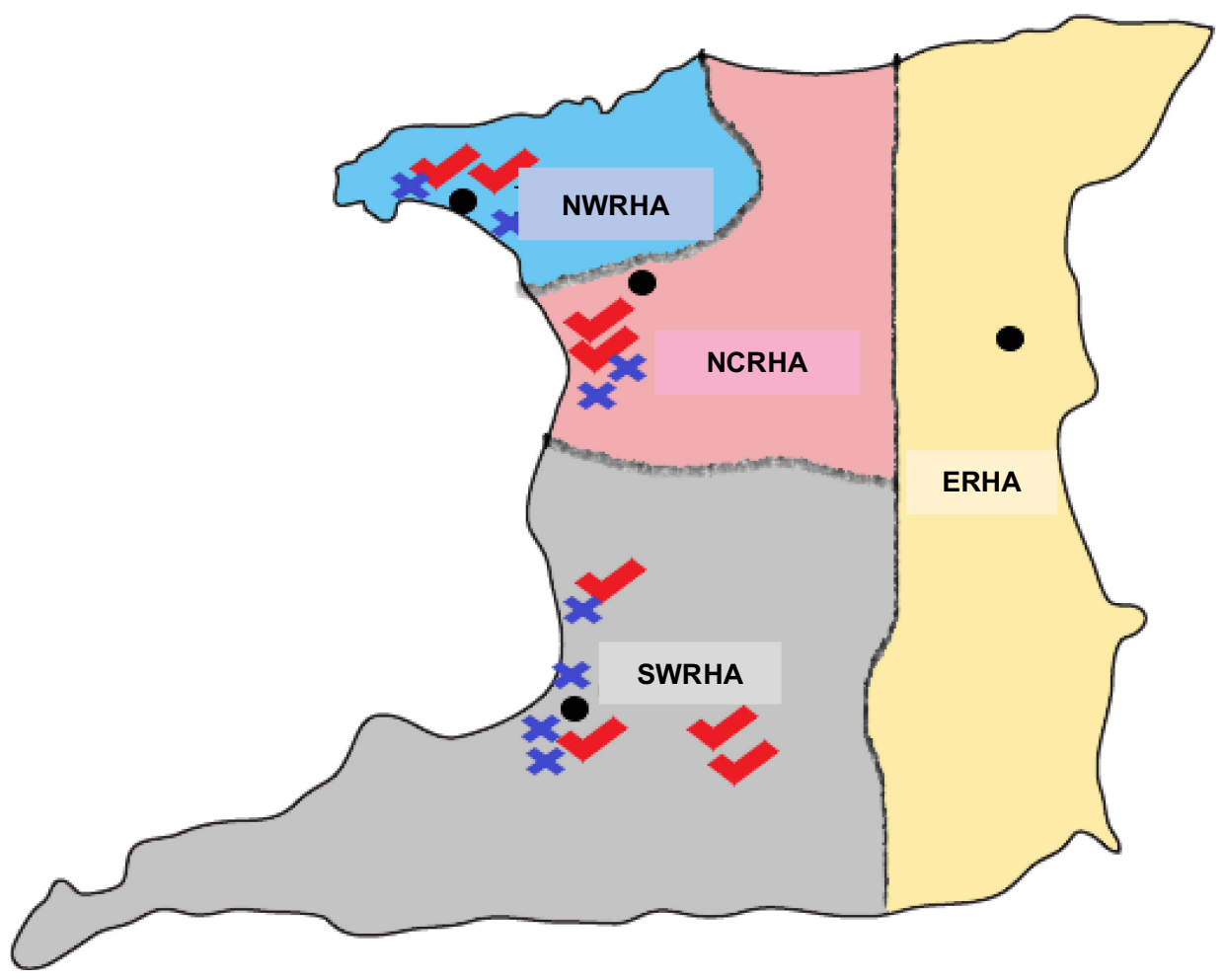

Figure I Stratified random sampling of private hemodialysis centers in Trinidad and Tobago.

Notes: - -Public hemodialysis centre; $\checkmark$ - Private hemodialysis centre; $x$ - Private hemodialysis centre.

Abbreviations: NCRHA, North Central Regional Health Authority; NWRHA, North West Regional Health Authority; ERHA, Eastern Regional Health Authority; SWRHA, South West Regional Health Authority; TRHA, Tobago Regional Health Authority.

high agreement with a gold standard. All patients in this study provided informed consent in writing. Participants were thoroughly counselled on the nature and undertakings of the research. They were also advised that they could refuse to participate in the study or refuse to continue further in the questionnaire. Questionnaires were administered in an interviewbased format and confidentiality was maintained. Hemodialysis patients were interviewed at their respective centres in a clinic setting using a consultation room with full privacy. Patients were approached after their hemodialysis session and those granting written consent and meeting inclusion criteria were administered the questionnaires. Renal transplant and peritoneal dialysis recipients were also interviewed in a similar manner by means of face-to-face interviews at the organ transplant unit and renal clinics, respectively. Patients were encouraged to answer truthfully and there was no prompting of responses by interviewers who were trained in the administration of all questionnaires. 


\section{Ethical Approval}

All permissions were obtained for public and private institutions. The ethics committees from the corresponding regional health authorities: North Central, North West, South West, Eastern and Tobago gave their approvals. The University of the West Indies ethics committee granted approval for this research.

\section{Data Entry and Analysis}

The statistics software Statistical Package for the Social Sciences (SPSS) version 24 and Microsoft EXCEL were used for data entry and editing prior to data analysis. Preliminary computations included calculating a Charlson's comorbidity index for each patient. This index categorizes patients according to their probability of surviving different diseases during the 10-year period subsequent to the date on which the index was computed. ${ }^{23}$ The lower the index, the greater the probability of survival.

Subsequently, SPSS version 24, MINITAB version 18 and STATA version 14 were used for both descriptive and inferential data analysis. Descriptive methods included frequency and percentage distribution tables and summary statistics. Inferential methods included 95\% confidence intervals and analysis of variance. Tukey range tests and robust test of means of total and domain scores of the Kidney Disease Quality of Life questionnaire were done. Pairwise multiple comparisons for subgroups and domain scores were performed. Ordinary least-squares regression model was done for the EuroQol questionnaire with corrections for age and gender among patients in different modalities of renal replacement therapy. Chi-square analysis was used to investigate Charlson's comorbidity index and significant associations. The reliability of the Kidney Disease Quality of Life questionnaire was tested with Cronbach's alpha.

\section{Results}

\section{Baseline Characteristics}

Figure 2 shows individuals at each stage of the study. The overall response rate was $95.8 \%$. The 16 patients who declined to participate were on hemodialysis. The proportion of patients on hemodialysis who self-funded their therapy is shown in Table 1 . In the dialysis group (Figure 3), most patients were 56-65 years. Reliability of the Kidney Disease Quality of Life questionnaire (Cronbach's alpha) was 0.988 .

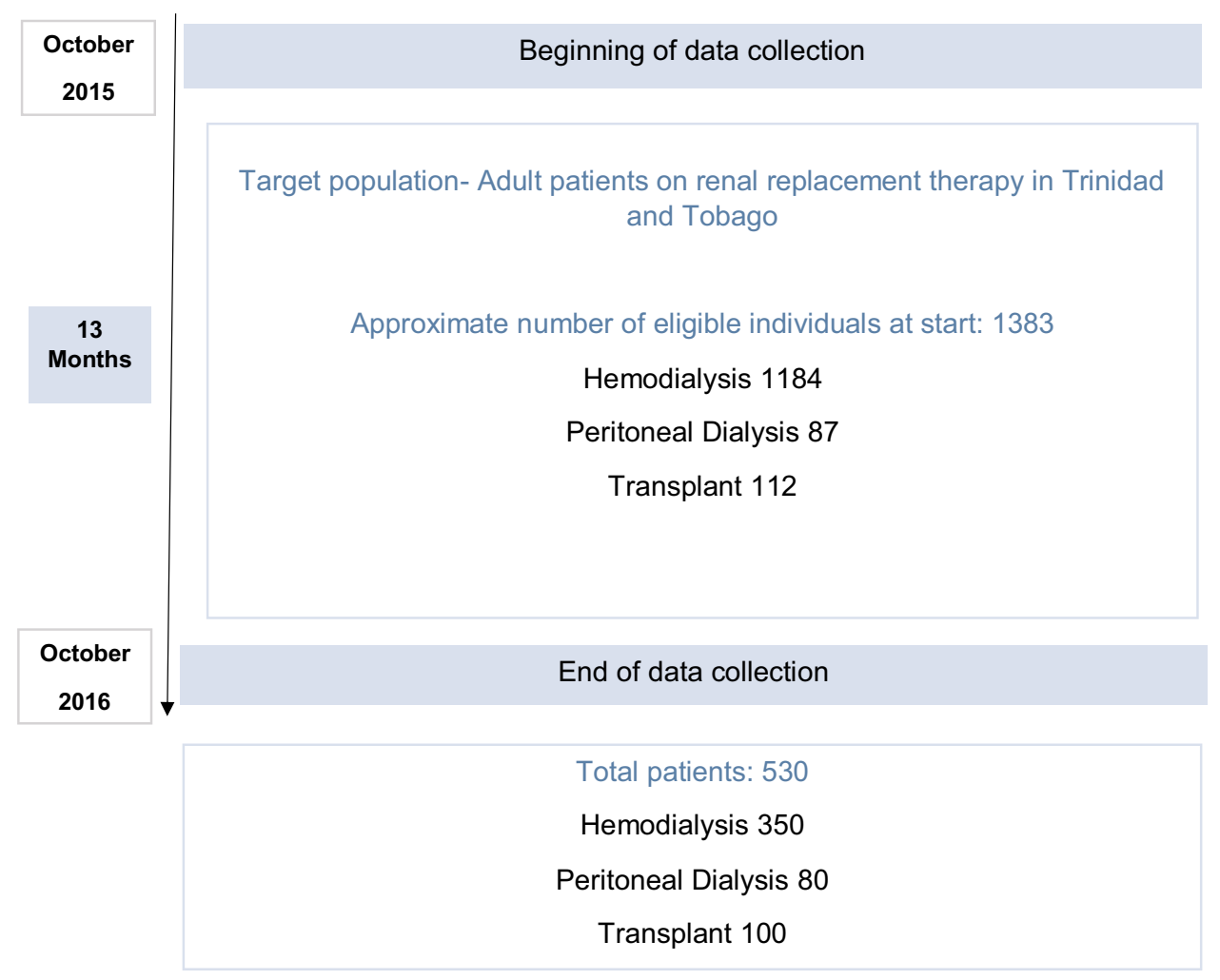

Figure 2 Individuals at each stage of study. Notes: $\downarrow$-Progression of time/months. 
Table I Source of Funding for Patients on Hemodialysis

\begin{tabular}{|l|l|l|}
\hline \multirow{2}{*}{$\begin{array}{l}\text { Source of } \\
\text { Funding }\end{array}$} & \multicolumn{2}{|l|}{ Mode of Therapy } \\
\cline { 2 - 3 } & \multicolumn{2}{|l|}{ Hemodialysis (H=350) } \\
\cline { 2 - 3 } & $\begin{array}{l}\text { Private Centre } \\
\text { Patients }\end{array}$ & $\begin{array}{l}\text { Public Centre } \\
\text { Patients }\end{array}$ \\
\hline $\begin{array}{l}\text { Government } \\
\text { funded }\end{array}$ & 252 & 86 \\
\hline Self-funded & 12 & 0 \\
\hline
\end{tabular}

Table 2 gives the frequency and percentage distribution of selected characteristics of the patients. As seen, they were predominantly male $(52.5 \%)$ and of IndoTrinbagonian descent $(51.5 \%)$. Patients were mostly of the 55-65 years of age category $(37.5 \%)$.

Chi-square analysis showed that Charlson's comorbidity index (and by association 10-year survival probability) was associated with sex $\left(\chi^{2}=8.66, \mathrm{p}=0.013\right)$, age $\left(\chi^{2}=\right.$ 43.6; $\mathrm{p} \leq 0.001)$, ethnicity $\left(\chi^{2}=339.7 ; \mathrm{p} \leq 0.001\right)$; and type of renal replacement $\left(\chi^{2}=66.7 ; \mathrm{p} \leq 0.001\right)$.

Underweight patients were predominantly on peritoneal dialysis and the prevalence of obesity was greater among hemodialysis patients (Figure 4). The self-reported cause of chronic kidney disease is seen in Figure 5. In $84 \%$ of persons, the diagnosis of chronic kidney disease was made when patients required renal replacement therapy.

Thirty-three percent of patients on hemodialysis had an arteriovenous fistula or graft $(\mathrm{AVF} / \mathrm{G})$ as their primary access type. Almost half of the patients with permanent catheters were managed for catheter-related blood stream infections within the last 5 years of the study period. Infective endocarditis was reported in $15 \%$ of those patients within the last 5 years of the study period. With

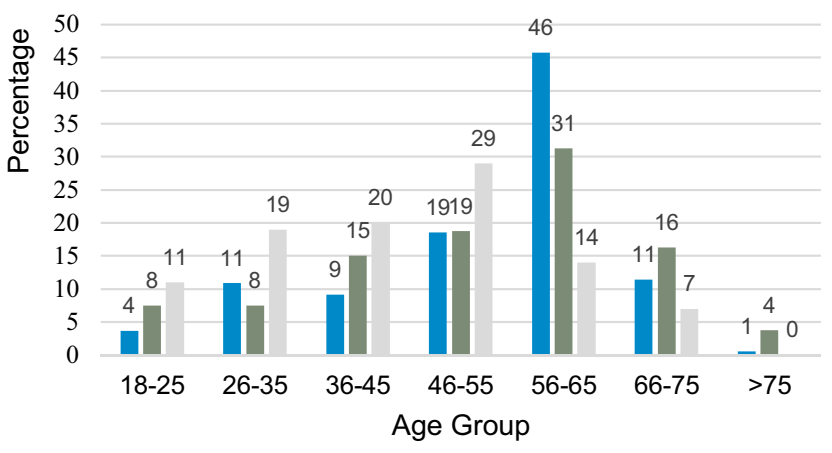

Figure 3 Age groups of patients on renal replacement therapy. Notes: - Haemodialysis; $\quad$-Peritoneal Dialysis; $\quad$-Transplant. respect to comorbidities, all patients with a Charlson's comorbidity index $\geq 6$ were on hemodialysis. No transplant or peritoneal dialysis patients had a Charlson's comorbidity index $\geq 6$. These patients constituted $15 \%$ of the total number of patients on hemodialysis. Patients on hemodialysis $>5$ years had lower mean physical component scores (43.7) on the Kidney Disease Quality of Life questionnaire than those on hemodialysis $\leq 5$ years. (64.8)

\section{Results of Analysis of Variance (ANOVA) and Pairwise Comparisons}

The Kidney Disease Quality of Life questionnaire total and domain scores were scaled to 100 . Table 3 shows mean and standard deviation of the physical component score, mental component score, symptoms and problems of kidney disease, burden of kidney disease, and effect of kidney disease subcomponent scores by demographic categories (age, ethnicity), Charlson's comorbidity index, income, employment status and mode of renal therapy.

Even though no trends or patterns could be discerned among the means, analysis of variance showed that there were statistically significant differences between the mean scores among the ethnic groups, among patients on different modalities, among patients with different Charlson's comorbidity index, income brackets and employment status. Table 3 shows pairwise comparisons where cell values with different lettering indicate significant differences with the group and where numbers with the same lettering indicate no statistically significant difference.

Table 4 shows analysis of variance for Kidney Disease Quality of Life scores and mode of renal replacement therapy. Analysis of variance methods shows statistically significant quality of life scores among hemodialysis patients and type of access. Table 5 also shows pairwise comparisons of statistically significant differences (different lettering) versus no differences (same lettering) in quality of life among hemodialysis patients and type of access used.

\section{EuroQol Results}

The mean visual analogue scale and mean index values seen in Table 6 were best among the transplant group followed by peritoneal dialysis and then hemodialysis $(\mathrm{p}=0.000)$. Table 7 shows that transplant patients perform better than hemodialysis patients based on both the EuroQol and index values. Supplementary Table 1 shows the EuroQol health states that were observed for the 3 
Table 2 Characteristics of Patients on Renal Replacement Therapy

\begin{tabular}{|c|c|c|c|c|c|}
\hline Characteristic & $\begin{array}{l}\text { All Modalities/ } \\
\text { Percent (\%) } \\
\text { Patients N=530 }\end{array}$ & $\begin{array}{l}\text { Hemodialysis/ } \\
\text { Percent (\%) } \\
\text { Patients H=350 }\end{array}$ & $\begin{array}{l}\text { Peritoneal Dialysis/ } \\
\text { Percent (\%) } \\
\text { Patients } P=\mathbf{8 0}\end{array}$ & $\begin{array}{l}\text { Renal Transplant/ } \\
\text { Percent (\%) } \\
\text { Patients } T=100\end{array}$ & $\mathrm{p}$ value \\
\hline Sex & & & & & 0.668 \\
\hline Male & 52.50 & 52.30 & 46.30 & 58.00 & \\
\hline Female & 47.50 & 47.70 & 53.70 & 42.00 & \\
\hline Ethnicity & & & & & $\leq 0.001$ \\
\hline Indo Trinidadian & 51.30 & 52.50 & 53.50 & 58.00 & \\
\hline Afro Trinidadian & 37.50 & 38.50 & 36.50 & 32.00 & \\
\hline Mixed & 10.00 & 7.50 & 9.00 & 9.00 & \\
\hline Other & 1.20 & 1.50 & 1.00 & 1.00 & \\
\hline Income/month & & & & & $\leq 0.001$ \\
\hline$\leq \$ 1000 \mathrm{TT}$ & 46.98 & 58.51 & 32.50 & 27.00 & \\
\hline$>\$ 1000 \mathrm{TT}, \leq \$ 4000 \mathrm{TT}$ & 12.83 & 15.37 & 11.25 & 1.00 & \\
\hline$>\$ 4000 \mathrm{TT}, \leq \$ 8000 \mathrm{TT}$ & 30.57 & 24.51 & 37.50 & 42.00 & \\
\hline$>\$ 8000 \mathrm{TT}, \leq 12,000 \mathrm{TT}$ & 9.62 & 1.77 & 18.75 & 30.00 & \\
\hline Employment & & & & & $\leq 0.001$ \\
\hline Not employed & 43.77 & 54.00 & 22.50 & 11.00 & \\
\hline Employed & 33.96 & 22.86 & 43.75 & 65.00 & \\
\hline Educational goals & 12.08 & 14.29 & 13.75 & 14.00 & \\
\hline Retired & 10.57 & 16.00 & 20.00 & 10.00 & \\
\hline Prior Mode of Renal & & & & & 0.526 \\
\hline Replacement Therapy & & & & & \\
\hline None & 81.90 & 98.57 & 78.75 & 20.00 & \\
\hline Hemodialysis & 16.22 & Not applicable & 17.50 & 76.00 & \\
\hline Peritoneal Dialysis & 0.56 & 0.00 & Not applicable & 4.00 & \\
\hline Renal Transplant & 1.32 & 1.43 & 3.75 & Not applicable & \\
\hline
\end{tabular}

groups in this study. Four EuroQol states were observed among transplant patients. Ninety-five percent of the transplant recipients were in the full health state (11111). None of the transplant recipients reported level three on any of the EuroQol dimensions. In comparison to population norms for age and gender in Trinidad and Tobago, the health state profile for transplant patients was better than the normal population. Table 6 shows the visual analogue scale and index values for the three groups. On both measures, the transplant group had the highest values and the hemodialysis group had the lowest values.

Table 7 shows the results of ordinary least-squares regression model for visual analogue scale and index values with controls for age and gender. Transplant is used as the reference category with dummy variables for peritoneal dialysis and hemodialysis. The coefficients for peritoneal dialysis and hemodialysis in these models are $-8.63,-25.74$ and $-0.08,-0.20$ for visual analogue scale and EuroQol, respectively. These coefficients indicate the size of the differences between transplant and the other two modalities. Peritoneal dialysis is associated with a reduction of 8.63 visual analogue-scale points, and a reduction of 0.08 in utility when compared with transplant recipients. Hemodialysis carries decrements of 25.74 visual analogue scale points and 0.20 in utility when compared to the transplant group.

\section{Discussion}

\section{Overview}

The Kidney Disease Quality of Life questionnaire domain scores and significantly associated variables included modality of renal replacement, Charlson's Comorbidity Index, ethnicity, income and employment status. Transplant patients performed the best in the Kidney Disease Quality of Life questionnaire and EuroQol. Patients on peritoneal dialysis had a better quality of life than 


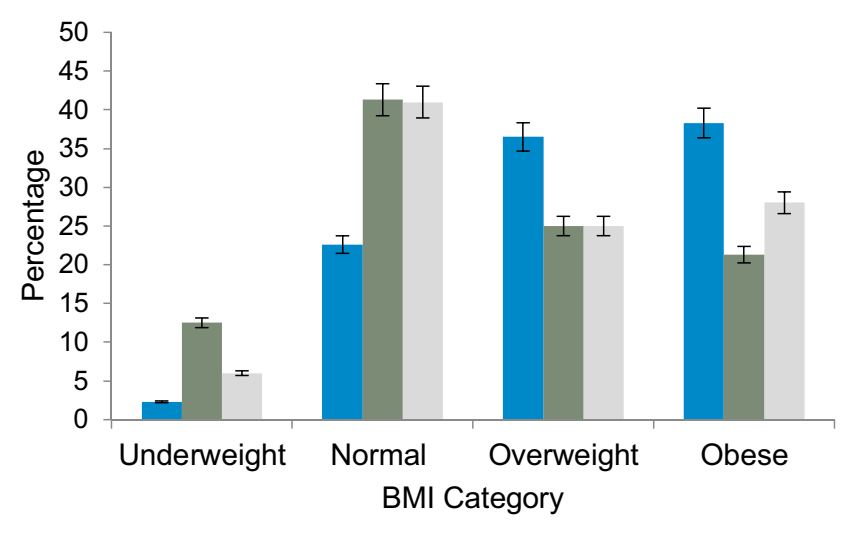

Figure 4 Body mass index (BMI) category and mode of therapy. Notes: _-Haemodialysis; _ - Peritoneal Dialysis; - Transplant.

hemodialysis patients. Among patients on hemodialysis, an arteriovenous fistula or graft significantly impacted their quality of life.

Quality of life is a difficult and complex construct to measure that involves the interplay of numerous factors and extends into all aspects of an individual's functioning. Wilson and Cleary provide a model that starts at a cellular level and progresses to the individual interacting with society. ${ }^{30}$ Quality of life not only encompasses genetics and the environment but also includes social, cultural, economic and psychological measurements. In assessing the success of therapy, quality of life and state of health have been used throughout the years as indicators of treatment outcome and subsequently can be employed to evaluate the cost-effectiveness of therapies.

In this population, about $90 \%$ of patients on renal replacement are on dialysis and two thirds of the hemodialysis patients have permanent catheters as their primary access type. These findings emphasize the importance of this study in the Caribbean population and the impact of the factors affecting quality of life. Robinson et al have shown differences in the patient population on renal replacement therapy across the continents. ${ }^{31}$ Countries studied were Central and Eastern Europe, Eastern and South Eastern Asia and the United States of America. ${ }^{31}$ In particular, it was seen that most of the patients in Japan on hemodialysis use an arteriovenous fistula. ${ }^{31}$ Japan and Norway utilize renal transplantation as their main mode of renal replacement therapy, while in Europe, less than $5 \%$ of patients with kidney disease are transplanted. ${ }^{31}$

\section{Biological Factors}

\section{Mode of Renal Replacement Therapy}

In 1985, Evans and colleagues measured the quality of life of patients undergoing dialysis and transplantation. They found that $79.1 \%$ of transplant patients were able to function at nearly normal levels compared to between $47.5 \%$ and $59.1 \%$ of dialysis patients depending on the type of dialysis. $^{32}$ In this study, it was found that patients who received renal transplants had better quality of life scores

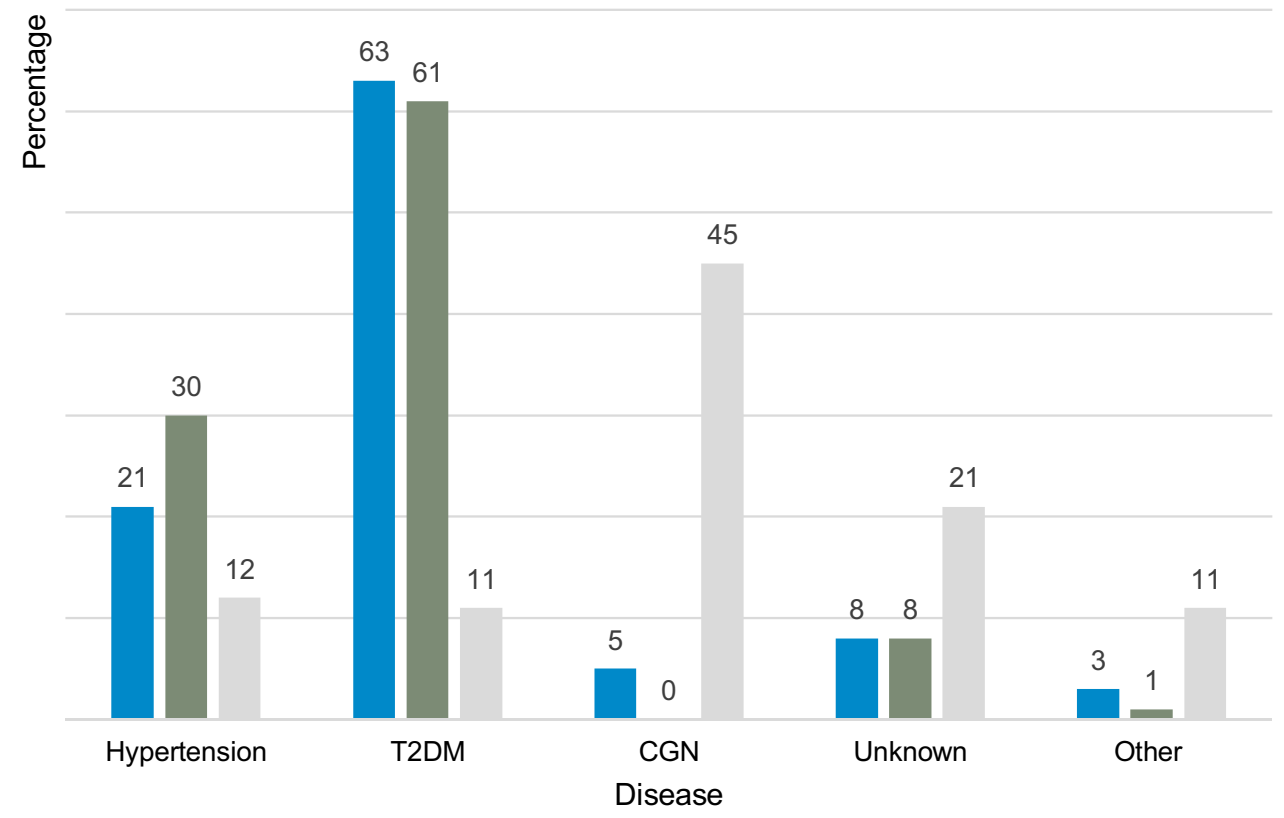

Figure 5 Self-reported cause of chronic kidney disease.

Notes: -Haemodialysis; _-Peritoneal Dialysis; -Transplant. Other, Polycystic kidney disease, Type I Diabetes Mellitus, Reflux nephropathy.

Abbreviations: T2DM, Type 2 diabetes mellitus; CGN, chronic glomerulonephritis. 


\begin{tabular}{|c|c|c|c|c|c|c|c|c|c|c|c|c|c|c|c|c|c|c|c|c|c|c|}
\hline 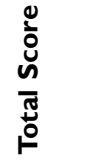 & $\begin{array}{l}\text { مू } \\
\text { ô }\end{array}$ & $\begin{array}{l}\infty \\
\substack{\infty \\
\infty \\
\infty}\end{array}$ & $\begin{array}{l}\stackrel{t}{\Delta} \\
\underline{\infty}\end{array}$ & $\frac{\nabla}{\mathrm{n}}$ & 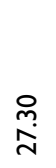 & $\begin{array}{l}\stackrel{\infty}{n} \\
\stackrel{n}{n}\end{array}$ & $\begin{array}{l}8 \\
\stackrel{+}{+}\end{array}$ & $\begin{array}{l}\tilde{n} \\
\stackrel{R}{R}\end{array}$ & స్ & $\begin{array}{l}\infty \\
\stackrel{\infty}{n} \\
\end{array}$ & $\begin{array}{l}\hat{\infty} \\
\stackrel{\leftrightarrow}{\sim} \\
\stackrel{\sim}{n}\end{array}$ & $\overline{\overline{0}}$ & $\begin{array}{l}\text { fo } \\
\stackrel{d}{\text { d }}\end{array}$ & $\begin{array}{l}\stackrel{\leftrightarrow}{\hat{n}} \\
\stackrel{\infty}{\infty}\end{array}$ & ๙ั & $\begin{array}{l}\overline{8} \\
\dot{0} \\
\text { vi }\end{array}$ & 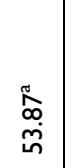 & $\underset{\tilde{\sim}}{\hat{\sim}}$ & 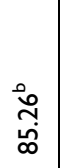 & $\begin{array}{l}\bar{\odot} \\
\stackrel{0}{0}\end{array}$ & $\frac{\breve{c}}{\infty}$ & ণ্ণি \\
\hline 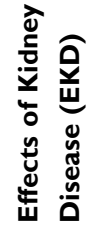 & 命 & 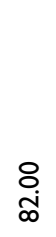 & $\frac{\stackrel{n}{\alpha}}{\tilde{N}}$ & $\underset{\substack{n \\
\kappa}}{n}$ & 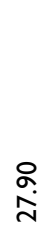 & 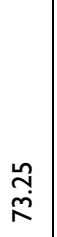 & $\begin{array}{l}\stackrel{\sim}{\hat{\sim}} \\
\stackrel{\infty}{\sim}\end{array}$ & $\frac{8}{i}$ & $\frac{\infty}{m}$ & 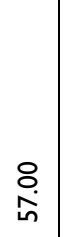 & $\begin{array}{l}\stackrel{0}{0} \\
\text { o. } \\
\text { N }\end{array}$ & 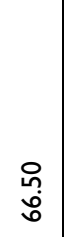 & $\begin{array}{l}\infty \\
\stackrel{\infty}{\infty}\end{array}$ & ষ্் & $\underset{\sim}{\widetilde{N}}$ & $\begin{array}{l}\overline{8} \\
\text { iो } \\
\text { i }\end{array}$ & 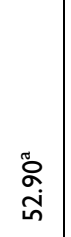 & $\begin{array}{l}\text { oे } \\
\stackrel{\omega}{0}\end{array}$ & 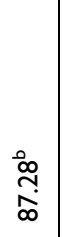 & 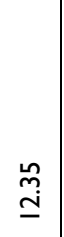 & $\begin{array}{l}\text { o } \\
\infty \\
\propto \\
\sigma\end{array}$ & $\underset{m}{\stackrel{m}{m}}$ \\
\hline
\end{tabular}

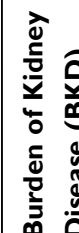

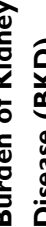

\section{¿}

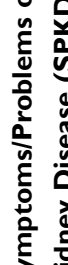

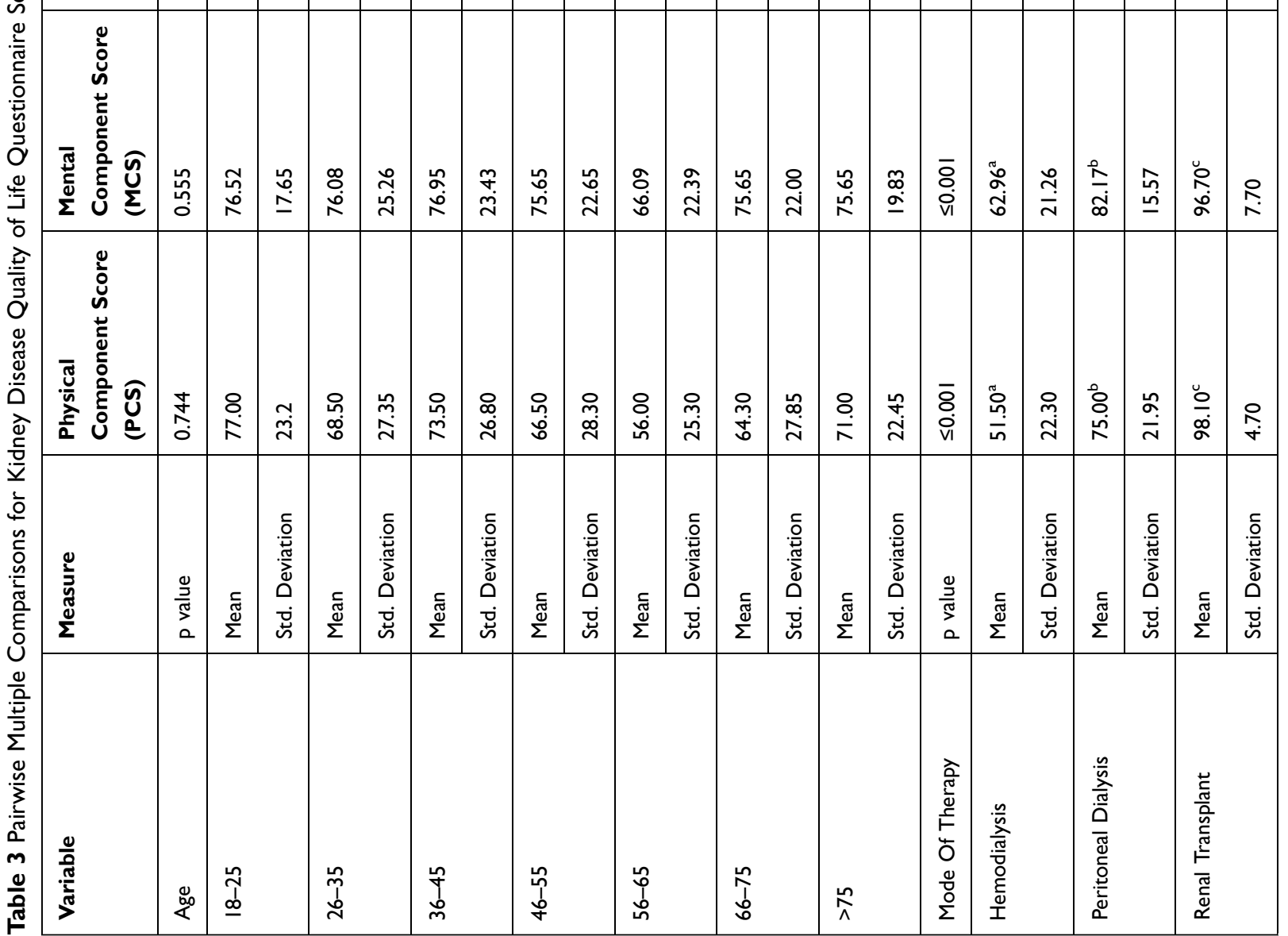




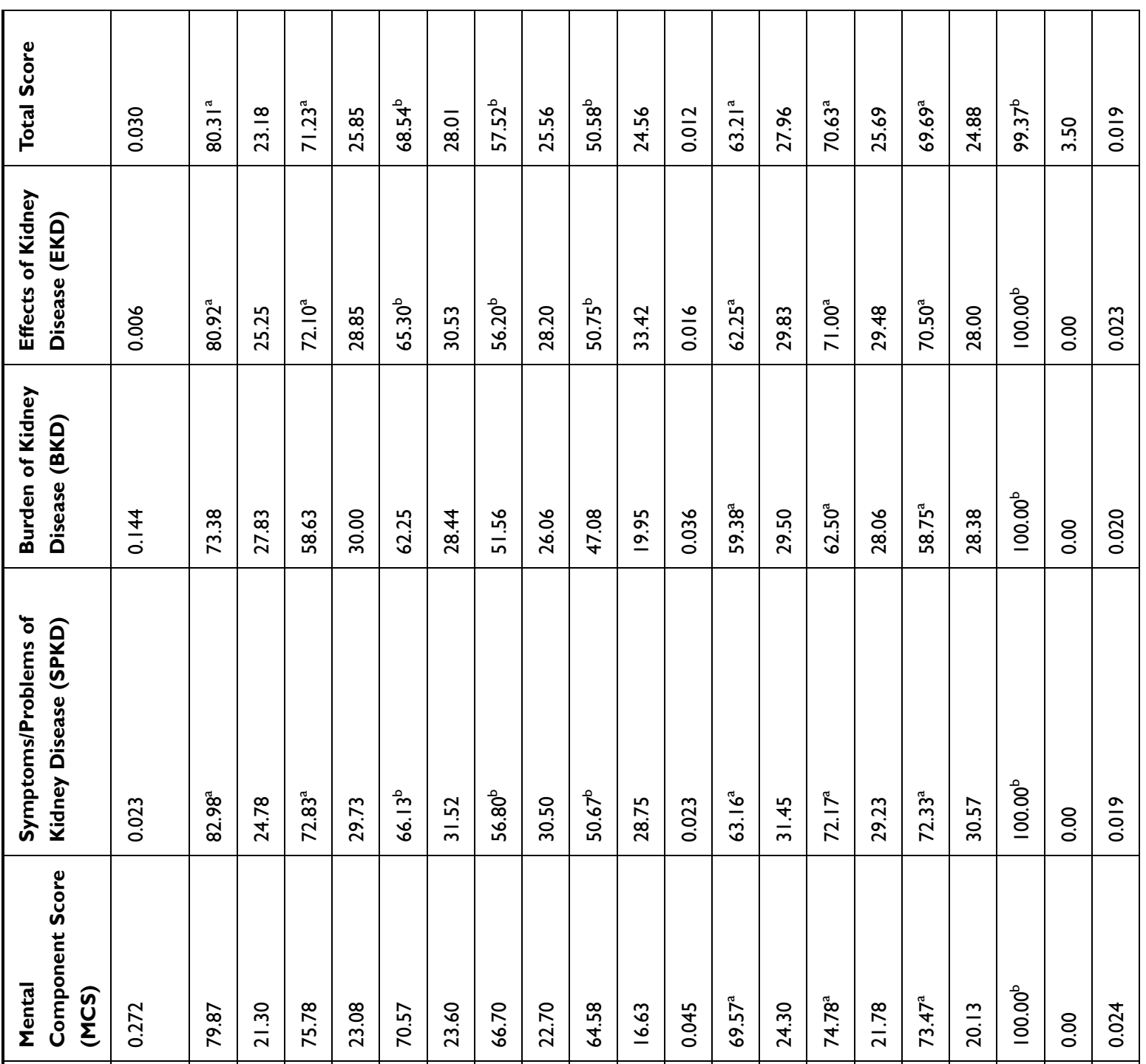

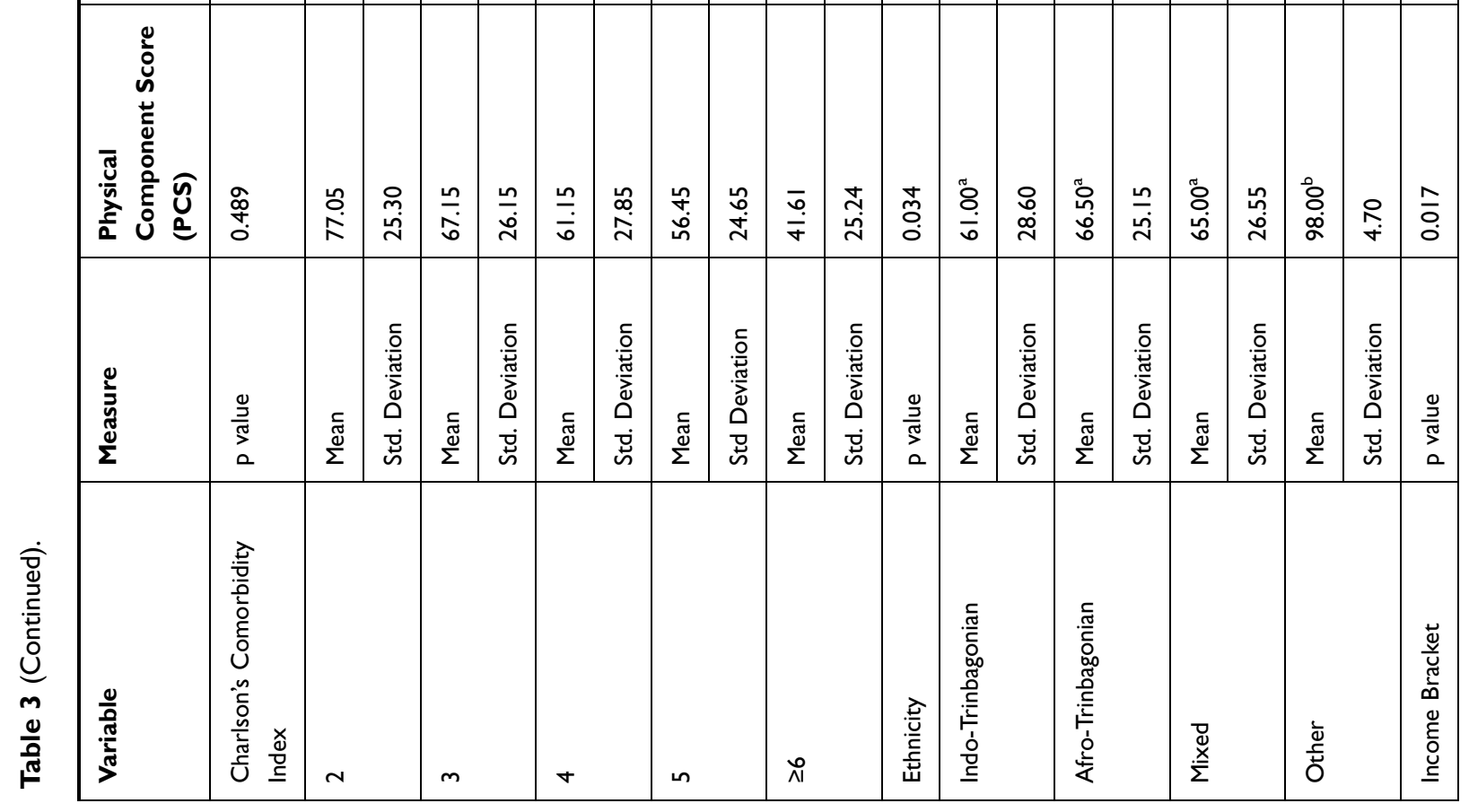




\begin{tabular}{|c|c|c|c|c|c|c|c|c|c|c|c|c|c|c|c|c|c|c|}
\hline 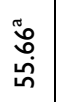 & $\stackrel{\bar{\alpha}}{\underline{\Lambda}}$ & 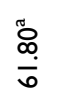 & $\stackrel{\stackrel{\circ}{N}}{\sim}$ & $\begin{array}{l}0 \\
\text { ò } \\
\text { ํ. }\end{array}$ & 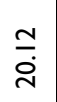 & 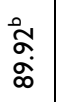 & 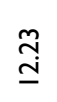 & $\begin{array}{l}\stackrel{2}{\hat{\alpha}} \\
\hat{\infty}\end{array}$ & 命 & $\frac{\infty}{0}$ & 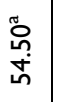 & $\begin{array}{c}\hat{\sigma} \\
\underset{\sim}{\sim}\end{array}$ & 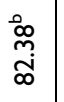 & 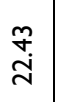 & 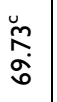 & $\begin{array}{l}\infty \\
\stackrel{\infty}{\circ} \\
\stackrel{0}{2}\end{array}$ & $\begin{array}{l}\stackrel{0}{\bar{R}} \\
\stackrel{1}{n}\end{array}$ & $\begin{array}{l}\stackrel{\alpha}{\alpha} \\
\underset{\sim}{N}\end{array}$ \\
\hline 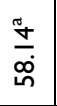 & 㐱 & 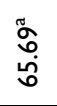 & & $\begin{array}{l}\stackrel{0}{2} \\
\substack{\infty \\
\infty}\end{array}$ & 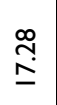 & $\frac{\stackrel{0}{n}}{\stackrel{a}{a}}$ & $\begin{array}{l}\stackrel{\tilde{H}}{\underline{\omega n}} \\
\underline{\underline{n}}\end{array}$ & \begin{tabular}{l}
0 \\
\multirow{2}{0}{} \\
$\infty$ \\
$\infty$ \\
$\infty$
\end{tabular} & 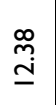 & $\frac{n}{0}$ & $\frac{\infty}{0}$ & 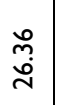 & $\begin{array}{l}\stackrel{0}{\Delta} \\
\text { هे } \\
\infty\end{array}$ & $\begin{array}{l}\hat{\stackrel{\sim}{*}} \\
\text {. }\end{array}$ & 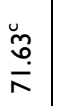 & $\begin{array}{l}\stackrel{\tilde{n}}{\hat{N}} \\
\underset{\sim}{\sim}\end{array}$ & 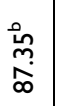 & $\underset{\underset{\sim}{\sim}}{\stackrel{R}{*}}$ \\
\hline 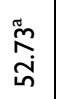 & 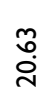 & 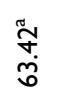 & $\frac{\stackrel{\leftrightarrow}{\rho}}{\stackrel{n}{N}}$ & $\begin{array}{l}\stackrel{0}{m} \\
\hat{R}\end{array}$ & $\begin{array}{l}\bar{m} \\
\underline{a}\end{array}$ & $\begin{array}{l}\text { مू } \\
\text { مू }\end{array}$ & $\frac{m}{\underline{\infty}}$ & $\begin{array}{l}\stackrel{\circ}{\circ} \\
\stackrel{0}{0} \\
\end{array}$ & 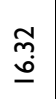 & శ్రి & $\frac{\stackrel{\infty}{m}}{\frac{m}{n}}$ & $\begin{array}{c}m \\
\stackrel{m}{\sim}\end{array}$ & 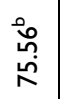 & $\begin{array}{l}\stackrel{ \pm}{d} \\
\stackrel{\sim}{\sim}\end{array}$ & $\begin{array}{l}\stackrel{u}{0} \\
\stackrel{\infty}{0} \\
\stackrel{0}{0}\end{array}$ & $\begin{array}{l}\hat{f} \\
\ddot{\sim}\end{array}$ & 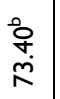 & 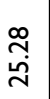 \\
\hline 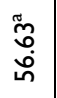 & 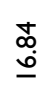 & 雚 & $\stackrel{\stackrel{\infty}{\stackrel{n}{\Lambda}}}{\underline{n}}$ & $\begin{array}{l}\stackrel{0}{\infty} \\
\stackrel{\leftrightarrow}{\wedge} \\
\stackrel{n}{n}\end{array}$ & $\begin{array}{l}\stackrel{0}{\infty} \\
\stackrel{\infty}{0}\end{array}$ & 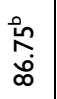 & $\begin{array}{l}\stackrel{\tilde{\sigma}}{\sigma} \\
\underline{\sigma}\end{array}$ & $\begin{array}{l}\stackrel{\circ}{\tilde{m}} \\
\stackrel{2}{\alpha}\end{array}$ & $\begin{array}{l}\stackrel{m}{q} \\
\stackrel{m}{9}\end{array}$ & $\begin{array}{l}\stackrel{+}{0} \\
\text { O̊. }\end{array}$ & 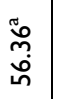 & $\frac{\infty}{\dot{\sim}}$ & 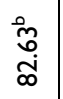 & $\begin{array}{l}\stackrel{\infty}{\stackrel{\sim}{\sim}} \\
\stackrel{n}{n}\end{array}$ & \begin{tabular}{l}
\multicolumn{1}{c}{} \\
0 \\
0 \\
0 \\
0
\end{tabular} & $\begin{array}{l}\stackrel{\circ}{+\sim} \\
\stackrel{\sim}{\sim}\end{array}$ & 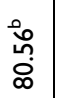 & 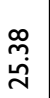 \\
\hline 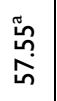 & $\begin{array}{l}\bar{m} \\
\underline{a}\end{array}$ & 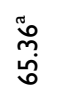 & $\begin{array}{l}\underset{\Xi}{\sigma} \\
\underline{a}\end{array}$ & 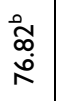 & 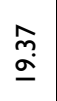 & 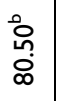 & $\begin{array}{l}\underset{N}{N} \\
\underline{0}\end{array}$ & $\begin{array}{l}\text { 䓍 } \\
\text { hू }\end{array}$ & 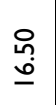 & 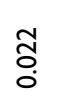 & 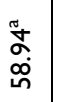 & 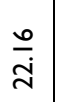 & 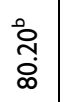 & $\frac{\hat{n}}{\bar{n}}$ & 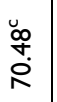 & $\underset{\underset{\sim}{\sim}}{\stackrel{\mathcal{N}}{*}}$ & 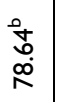 & $\begin{array}{l}\tilde{N} \\
\stackrel{\sim}{\sim}\end{array}$ \\
\hline 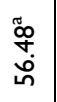 & $\begin{array}{l}\stackrel{\tilde{N}}{\hat{\rho}} \\
\underline{\underline{\rho}}\end{array}$ & 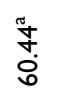 & $\begin{array}{l}\bar{\alpha} \\
\stackrel{\underline{m}}{ }\end{array}$ & $\underset{\hat{N}}{\stackrel{R}{n}}$ & $\begin{array}{l}\tilde{n} \\
\stackrel{\leftrightarrow}{\circ}\end{array}$ & $\begin{array}{l}\text { مे } \\
\text { ஸे } \\
\text { के }\end{array}$ & 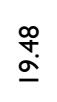 & $\begin{array}{l}\stackrel{0}{\infty} \\
\stackrel{\infty}{\infty}\end{array}$ & $\begin{array}{l}\stackrel{0}{0} \\
\underline{\infty} \\
\underline{\infty}\end{array}$ & $\frac{m}{0}$ & 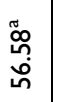 & $\frac{\tilde{n}}{\sim}$ & $\begin{array}{l}\stackrel{2}{\circ} \\
\stackrel{\infty}{\infty} \\
\infty\end{array}$ & $\begin{array}{l}\tilde{0} \\
\underset{\sim}{\sim}\end{array}$ & 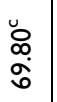 & $\begin{array}{l}\stackrel{\infty}{\sim} \\
\stackrel{\omega}{\sim}\end{array}$ & 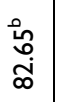 & 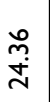 \\
\hline 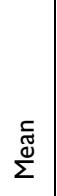 & 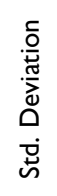 & 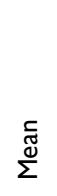 & 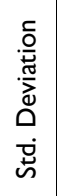 & $\frac{\stackrel{\Xi}{\mathbb{J}}}{\Sigma}$ & 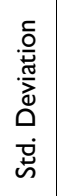 & $\frac{\widetilde{\varpi}}{\Sigma}$ & 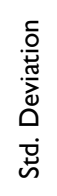 & 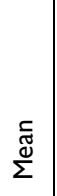 & 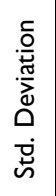 & $\begin{array}{l}\frac{0}{\frac{\partial}{5}} \\
\frac{N}{2} \\
0\end{array}$ & $\frac{\widetilde{\Xi}}{\Sigma}$ & 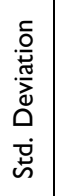 & $\frac{\sqrt{\tilde{\varpi}}}{\Sigma}$ & 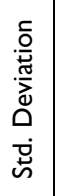 & 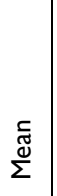 & 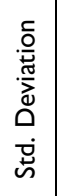 & $\frac{\sqrt{\varpi}}{\sum}$ & 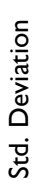 \\
\hline $\begin{array}{l}\vdash \\
\stackrel{\circ}{\circ} \\
\frac{O}{A} \\
\text { vi }\end{array}$ & & 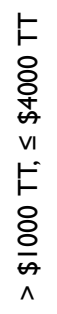 & & 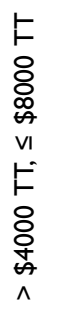 & & 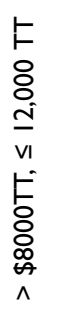 & & 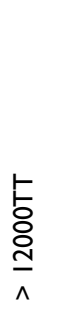 & & 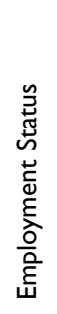 & 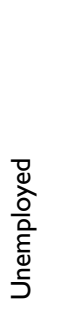 & & 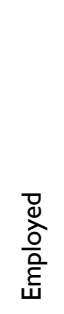 & & 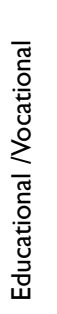 & & 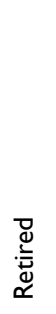 & \\
\hline
\end{tabular}


Table 4 Analysis of Variance for Kidney Disease Quality of Life Subcomponent Scores

\begin{tabular}{|l|l|l|l|l|l|l|}
\hline \multicolumn{2}{|l|}{ Dependent Variable } & Sum of Squares & df & Mean Square & F & P \\
\hline Physical Component Score (PCS) & Mode of renal replacement & 2044.44 & 3 & $68 I .48$ & 48.10 & $\leq 0.001$ \\
\hline Mental Component Score (MCS) & Mode of renal replacement & 2104.72 & 3 & 701.58 & 38.71 & $\leq 0.001$ \\
\hline Burden of Kidney Disease (BKD) & Mode of renal replacement & 2217.44 & 3 & 739.15 & 100.53 & $\leq 0.001$ \\
\hline Symptoms/Problems of Kidney Disease (SPKD) & Mode of renal replacement & $43,102.58$ & 3 & $14,367.53$ & 85.61 & $\leq 0.001$ \\
\hline Effects of Kidney Disease (EKD) & Mode of renal replacement & $17,077.04$ & 3 & 5692.35 & 84.62 & $\leq 0.001$ \\
\hline TOTAL & Mode of renal replacement & $226,222.19$ & 3 & $75,407.40$ & 100.53 & $\leq 0.001$ \\
\hline
\end{tabular}

compared with dialysis patients (Table 3). Peritoneal dialysis patients performed better than hemodialysis patients. Renal transplant patients also achieved higher scores in the disease-specific domains of the Kidney Disease Quality of Life questionnaire than dialysis patients. In the hemodialysis and peritoneal dialysis groups, the burden of kidney disease was the greatest challenge for patients (Table 3). In the transplant group, the mental domain subset had the lowest score compared to other domains of the Kidney Disease Quality of Life questionnaire. In patients with end-stage renal disease, the option of dialysis is still a great challenge for patients and physicians and institution of measures to improve quality of life for patients on peritoneal dialysis and hemodialysis is necessary. This study can guide decision makers with the potential solutions to assist with disease burden.

Some studies have shown that renal transplant recipients have better quality of life scores than patients on peritoneal dialysis and hemodialysis. ${ }^{1,2,8,14}$ Other studies show diverse outcomes, ${ }^{10,11,13,15}$ while some have not explored other factors besides mode of therapy that may attribute to a good quality of life. ${ }^{1,2,10-12,14}$ A meta-analysis done on the quality of life of patients on renal replacement therapy concluded that hemodialysis and peritoneal dialysis patients tend to have an inferior quality of life when compared to transplant recipients. ${ }^{12}$ Quality of life was worse for hemodialysis compared to peritoneal dialysis patients. ${ }^{2,12}$ This was also found in this study (Table 3).

Table 5 Pairwise Multi-Comparison for Patients on Hemodialysis and Primary Access Type

\begin{tabular}{|c|c|c|c|c|c|c|c|}
\hline Access Type & Measure & $\begin{array}{l}\text { Physical } \\
\text { Component } \\
\text { Score (PCS) }\end{array}$ & $\begin{array}{l}\text { Mental } \\
\text { Component } \\
\text { Score } \\
\text { (MCS) }\end{array}$ & $\begin{array}{l}\text { Symptoms/ } \\
\text { Problems of } \\
\text { Kidney Disease } \\
\text { (SPKD) }\end{array}$ & $\begin{array}{l}\text { Burden of } \\
\text { Kidney } \\
\text { Disease } \\
\text { (BKD) }\end{array}$ & $\begin{array}{l}\text { Effects of } \\
\text { Kidney } \\
\text { Disease } \\
\text { (EKD) }\end{array}$ & Total \\
\hline & $p$ value & $\leq \mathbf{0 . 0 0 I}$ & $\leq \mathbf{0 . 0 0 I}$ & $\leq 0.001$ & $\leq 0.001$ & $\leq \mathbf{0 . 0 0 I}$ & $\leq \mathbf{0 . 0 0 1}$ \\
\hline \multirow[t]{2}{*}{ Av Fistula $N=108$} & Mean & $65.40^{\mathrm{a}}$ & $78.57^{\mathrm{a}}$ & $79.65^{\mathrm{a}}$ & $69.56^{\mathrm{a}}$ & $77.58^{\mathrm{a}}$ & $76.62^{\mathrm{a}}$ \\
\hline & Std. Deviation & 16.10 & 15.96 & 23.67 & 20.25 & 24.58 & 19.23 \\
\hline \multirow[t]{2}{*}{ Av Graft $N=9$} & Mean & $57.20^{\mathrm{a}}$ & $68.13^{a}$ & $76.48^{a}$ & $73.63^{\mathrm{a}}$ & $77.23^{\mathrm{a}}$ & $73.16^{\mathrm{a}}$ \\
\hline & Std. Deviation & 11.75 & 15.65 & 30.27 & 33.75 & 28.73 & 25.07 \\
\hline \multirow{2}{*}{$\begin{array}{l}\text { Permanent } \\
\text { Catheter N=229 }\end{array}$} & Mean & $42.10^{\mathrm{b}}$ & $55.74^{b}$ & $40.68^{b}$ & $36.63^{b}$ & $40.68^{b}$ & $42.77^{b}$ \\
\hline & Std. Deviation & 17.80 & 19.74 & 20.30 & 14.25 & 18.00 & 15.94 \\
\hline \multirow[t]{2}{*}{ Other $\mathrm{N}=4$} & Mean & $32.50^{\mathrm{b}}$ & $45.65^{b}$ & $23.75^{b}$ & $26.25^{\mathrm{b}}$ & $33.75^{b}$ & $31.45^{b}$ \\
\hline & Std. Deviation & 8.65 & 12.52 & 3.43 & 7.88 & 10.10 & 6.59 \\
\hline
\end{tabular}

Notes: ${ }^{a, b}$ Cell values with different lettering indicate significant differences and cell values with the same lettering indicate no statistically significant difference with the group. 
Table 6 Mean Visual Analogue Scale and Index Values Using EuroQol for Patients on Renal Replacement

\begin{tabular}{|l|l|l|l|}
\hline \multirow{2}{*}{ Measures } & \multicolumn{2}{|l|}{ Mode of Therapy } & Transplant \\
\cline { 2 - 4 } & Hemodialysis & Peritoneal Dialysis & 88.25 \\
\hline Mean visual analogue scale & 62.00 & 79.13 & 1.19 \\
Std Error & 0.74 & 1.46 & $85.90-90.60$ \\
$95 \%$ Confidence Interval & $60.54-63.46$ & $76.26-81.99$ & 0.99 \\
Mean Index & 0.78 & 0.90 & 0.00 \\
Std Error & 0.01 & 0.02 & $0.99-0.99$ \\
$95 \%$ Confidence Interval & $0.76-0.80$ & $0.87-0.93$ & \\
\hline
\end{tabular}

Peritoneal dialysis requires a patient to have good social support and adequate facilities in the home environment to perform the procedure on a daily basis. The medical social worker plays an integral role in deciding candidacy. Health care workers also meticulously train patients and their families regularly.

In the EuroQol health state, transplant recipients actually performed better than the age and gender adjusted population norms for Trinidad and Tobago. Renal transplant recipients performed the best on the visual analogue scale and index values. Ninety-five percent of transplant recipients were in state 11111, the best state of health. Supplementary Figure 1 shows that transplant recipients reported less problems than the normal population. This finding can be investigated in a future study. The ordinary least-squares model in Table 7 shows that the health status of transplant patients is considerably better than that of peritoneal dialysis and hemodialysis patients. Ceteris paribus, moving a patient from hemodialysis to transplant, can result in an increase in utility of 0.2 and over 25 visual analogue-scale points, based on the population in this study. Similarly, moving a patient from peritoneal dialysis to transplant will result in an increase in utility of 0.08 and 8.6 visual analogue-scale points. The relative sizes of the peritoneal dialysis and haemodialysis coefficients in Table 7 also highlight the considerable difference in health

Table 7 Visual Analogue Scale and Index Values Using Ordinary Least-Squares Regression and Robust Standard Errors of Transplant Recipients Compared to Patients on Hemodialysis and Peritoneal Dialysis

\begin{tabular}{|l|l|l|l|l|l|}
\hline Visual Analogue Scale & Coefficient & Standard Error & P>t & \multicolumn{2}{l|}{$95 \%$ Confidence Interval } \\
\cline { 3 - 6 } & & & & Lower \\
\hline Age & -0.53 & 0.43 & 0.22 & -1.36 & 0.31 \\
\hline Gender & -0.41 & 1.17 & 0.73 & -2.71 & 1.89 \\
\hline Peritoneal dialysis & -8.63 & 2.05 & 0.00 & -12.66 & -4.59 \\
\hline Hemodialysis & -25.74 & 1.58 & 0.00 & -28.84 & -22.65 \\
\hline Constant & 90.61 & 2.60 & 0.00 & 85.51 & 95.7 \\
\hline Index & Coefficient & Standard Error & P>t & $95 \%$ Confidence Interval \\
\cline { 3 - 6 } & & & & Lower & Upper \\
\hline Age & -0.01 & 0.00 & 0.01 & -0.02 & -0.00 \\
\hline Gender & -0.00 & 0.01 & 0.93 & -0.03 & 0.02 \\
\hline Peritoneal dialysis & -0.08 & 0.02 & 0.00 & -0.13 & -0.04 \\
\hline Hemodialysis & -0.20 & 0.02 & 0.00 & -0.24 & -0.17 \\
\hline Constant & 1.04 & 0.00 & 0.97 & 1.09 \\
\hline
\end{tabular}


status between peritoneal dialysis and hemodialysis. That is, hemodialysis represents a considerably larger health decrement than peritoneal dialysis for this group.

Renal transplant recipients were also maintained on their therapy for longer periods than persons on other forms of therapy. Using a period of 5 years on renal replacement therapy, $8 \%$ of patients were on hemodialysis, while about one third of all transplant recipients had functioning grafts. These findings may be due to a number of reasons including comorbidities, age and type of access among this group. Renal transplantation when compared to other forms of renal replacement therapy is associated with fewer hospitalizations and death influencing the cost-effectiveness of this modality around the world. ${ }^{33,34}$

Patients on hemodialysis $>5$ years had lower mean physical component scores on the Kidney Disease Quality of Life questionnaire. In a Japanese study, physical scores on quality of life became worse as dialysis vintage lengthened. ${ }^{35}$

Renal transplantation may be the most physiologically similar to one's body as a mode of renal replacement therapy. Among transplant recipients, immunologic similarity can further be assessed with haplotype match between donor and recipient. Transplantation is also the least time-consuming method for all modalities. Hemodialysis patients have approximately 3 sessions of hemodialysis per week, while peritoneal dialysis patients undergo dialysis sessions at their home.

\section{Lifestyle Diseases and Comorbidities}

Lifestyle diseases among dialysis patients were the primary causes of kidney disease. Healthy lifestyle influences quality of life. ${ }^{36}$ During this study, it was shown that among the dialysis patients, the main causes of renal failure were type 2 diabetes mellitus or hypertension. However, in renal transplant patients, chronic glomerulonephritis was the main self-reported cause of chronic kidney disease. Over $80 \%$ of patients were diagnosed with kidney disease when renal replacement was necessary. This finding exposes the inadequacies of screening and the necessity for better strategies for preventing and treating lifestyle diseases in our setting.

Patients on hemodialysis also had more comorbidities than patients on other types of renal replacement. A Charlson's comorbidity index $\geq 6$ equivalent to a 10 -year survival probability of 0 was found only among the hemodialysis group. Patients with a Charlson's comorbidity index $\leq 3$ had significantly better mean symptoms and problems of kidney disease, effect of kidney disease and total scores.

\section{AVF/G for Hemodialysis}

Patients with an AVF/G performed better in all domains of the Kidney Disease Quality of Life questionnaire when compared to patients with permanent catheters (Table 5). In the burden of kidney disease subset, patients with an $\mathrm{AVF} / \mathrm{G}$ had similar scores to those on peritoneal dialysis. It has been shown that this access type is not only costefficient but offers a better quality of life for patients because of fewer complications than a permanent catheter. $^{37,38}$ Policy guidelines and support networks can therefore be improved for prompt referral and early surgery for an $\mathrm{AVF} / \mathrm{G}$ when choosing hemodialysis.

\section{Adiposity Stores}

Increased adiposity may be favourable for patients on hemodialysis, providing an anti-inflammatory benefit during times of cellular stress. ${ }^{39-43}$ Studies have shown improved survival and a better quality of life of patients with a BMI $>25$ on hemodialysis. ${ }^{41-43}$

\section{Age, Gender and Ethnicity}

Figure 3 shows that renal transplant recipients are younger. This may mean a greater selectivity among these patients which can ultimately influence survival rates, risk of complications and comorbidities among other factors. The aetiology of kidney disease among transplant recipients in our population is also different from patients on dialysis. Figure 5 shows that dialysis patients' main selfreported causes of kidney disease were type 2 diabetes mellitus and hypertension, while transplant recipients reported chronic glomerulonephritis. The presence of other comorbidities associated with these lifestyle diseases among the older dialysis patients can impact the complications associated with dialysis like catheter-related infections.

Supplementary Figure 1 for the EuroQol questionnaire shows that younger patients reported fewer problems in the hemodialysis group in both male and female. A similar trend is seen in the normal population where younger patients report fewer problems. A study that looked at patients on hemodialysis showed improved quality of life in younger patients ${ }^{44}$ Older female patients on peritoneal dialysis reported fewer problems than those in the younger age groups, while the extremes of age among male peritoneal dialysis patients reported more problems. Male 
transplant recipients in the 18 to 24 years group and 45-54 years group reported more problems.

Patients falling into the category of "other" for ethnicity had significantly greater mean quality of life scores than the remaining patients. In this study, patients categorized into this group were either Chinese or Syrian descent. These patients constituted $1.2 \%$ of all persons on renal replacement therapy $(1 \% \mathrm{~T}, 1 \% \mathrm{PD}, 1.5 \% \mathrm{HD})$.

\section{Social Factors Employment}

Employment status significantly influenced quality of life. The majority of the employed population on renal replacement were transplant recipients followed by patients on peritoneal dialysis (Table 3 ). It is possible that patients receiving transplants were able to take advantage of employment opportunities because of more time availability. Retired persons also had significantly better mean Kidney Disease Quality of Life questionnaire scores than those pursuing educational goals or those that were unemployed. In Canada, in the first 2 years after renal replacement therapy, employment opportunities were the best in the transplant subset. ${ }^{10}$ Table 2 also shows that in the occupation category of managers and professionals, transplant recipients formed the majority of these categories followed by patients on hemodialysis.

\section{Economic Status}

Like employment, income is another factor affecting the quality of life of patients receiving renal replacement therapy. Alvares and colleagues also saw this in another study. $^{8}$ In this population, patients earning more than $\$ 4000$ Trinidad and Tobago dollars monthly (equivalent to approx. 600 US Dollars) had better mean quality of life scores.

\section{Renal Replacement Therapy Services}

Options for renal replacement therapy include renal transplantation, peritoneal dialysis and hemodialysis. Similar to worldwide health care systems, each mode of therapy has specific requirements and criteria before initiation, some being more rigorous than others.

There are approximately 1200 persons presently on haemodialysis in Trinidad and Tobago. There are nearly the same number of patients on peritoneal dialysis during the time data were collected and now. From the inception of the National Organ Transplant Unit in January 2006 to the time data were collected (October 2015), there had been 148 renal transplantations done from living and deceased donors. At present, the unit has provided 194 kidney transplants.

Hemodialysis in our population is associated with the poorest quality of life and the most problems reported by patients using the Kidney Disease Quality of Life questionnaire and EuroQol questionnaires. The 17 visual analogue-scale points difference and 0.12 utility for patients on hemodialysis compared to peritoneal dialysis suggests that a transition to peritoneal dialysis can significantly affect health status. Given the similar number of patients on peritoneal dialysis between the time of data collection and present, there is a need for strategies to be implemented to allow greater advocacy and access to peritoneal dialysis.

Certain modes of renal replacement therapy in our setting are associated with multiple checkpoints and prerequisites that should be satisfied, greater engagement of patients and their families and better support systems. As a result, these modalities of therapy like renal transplantation and peritoneal dialysis may produce patients that are more likely to adhere to therapy and management of comorbidities. Table 8 demonstrates the requirements and factors implicated in this study for each modality of renal replacement therapy in our population.

The renal transplant recipients' main self-reported causes of kidney disease was chronic glomerulonephritis while dialysis patients reported type 2 diabetes and hypertension. Chi-square analysis showed that Charlson's comorbidity index (and by association 10-year survival probability) was associated with the type of renal replacement $\left(\chi^{2}=66.7 ; \mathrm{p} \leq 0.001\right)$. There may be selectivity of patients for renal transplantation as a mode of renal replacement. Ceiling effects (present when $>15 \%$ of patients achieve the maximum possible score) were seen for the transplant subgroup with the EuroQol states. Fifty-nine percent of patients on peritoneal dialysis and $20 \%$ of patients on hemodialysis achieved a state of 11111 in the EQ-5D-3L also demonstrating ceiling effects. The Kidney Disease Quality of Life questionnaire domain and total scores did not show ceiling effects among subgroups. In a study of renal transplant patients in the United States, neither ceiling nor floor effects were noted for the Physical Component Score or Mental Component Score. ${ }^{46}$

\section{Limitations and Future Studies}

Renal clearances during peritoneal dialysis and hemodialysis can be investigated in further studies as this will establish the efficiency of dialysis for patients. Dialysis 
Table 8 Factors Implicated in the Initiation of Renal Replacement Therapy

\begin{tabular}{|c|c|c|c|}
\hline \multirow{2}{*}{$\begin{array}{l}\text { Factors Implicated } \\
\text { in Therapy }\end{array}$} & \multicolumn{3}{|l|}{ Mode of Therapy (Chronic Setting) } \\
\hline & Hemodialysis & Peritoneal Dialysis & Renal Transplant \\
\hline Government funding & Yes & Yes & Yes \\
\hline $\begin{array}{l}\text { Multidisciplinary } \\
\text { approach }\end{array}$ & Minimal & Minimal & $\begin{array}{l}\text { Management of comorbidities by respective } \\
\text { specialists }\end{array}$ \\
\hline Social support & $\begin{array}{l}\text { Medical social worker evaluates } \\
\text { socioeconomic status to qualify for } \\
\text { government funding }\end{array}$ & $\begin{array}{l}\text { Multiple medical social worker } \\
\text { evaluations }\end{array}$ & $\begin{array}{l}\text { Multiple medical social worker evaluations } \\
\text { and psychiatric evaluations }\end{array}$ \\
\hline $\begin{array}{l}\text { Evaluation of home } \\
\text { and surroundings }\end{array}$ & Not required & $\begin{array}{l}\text { Required as therapy is done at } \\
\text { home }\end{array}$ & Not required \\
\hline Family integration & $\begin{array}{l}\text { Minimal- interaction with patient and } \\
\text { hemodialysis nurses }\end{array}$ & $\begin{array}{l}\text { Yes- adequate family meetings } \\
\text { with social worker and } \\
\text { peritoneal dialysis nurses }\end{array}$ & $\begin{array}{l}\text { Yes-multiple family meetings with social } \\
\text { worker and transplant unit }\end{array}$ \\
\hline $\begin{array}{l}\text { Counselling on } \\
\text { therapy }\end{array}$ & Counselling by hemodialysisnurse & $\begin{array}{l}\text { Counselling by peritoneal } \\
\text { dialysis nurse }\end{array}$ & $\begin{array}{l}\text { Educational lectures pre and post-transplant } \\
\text { by transplant coordinators Counselling by } \\
\text { multidisciplinary team }\end{array}$ \\
\hline Ethical assessment & Not required & Not required & Required \\
\hline $\begin{array}{l}\text { Minimal time interval } \\
\text { to initiate therapy } \\
\text { (state funded) }\end{array}$ & I-3 months & $3-6$ months & 6 months -1 year \\
\hline
\end{tabular}

adequacy as a standard measure was not studied. Quality evaluations and protocols instituted by the health sector and established in each facility were relied upon for the adequacy of dialysis. These are monitored on a regular basis in each institution.

Lindsay et al studied minutes to recovery after a haemodialysis session. ${ }^{47}$ There were significant correlations between time to recovery and fatigue, dialysis stress and disease stress. ${ }^{47}$ Minutes to recovery is a useful tool in evaluating patients at hemodialysis centres in addition to quality of life questionnaires. This question can also be employed in hemodialysis quality of life studies in the Trinidad and Tobago population.

The quality of life and health state of patients who were diagnosed with end stage renal disease and do not wish for renal replacement therapy can be analysed as a further subgroup. Quality of life of the normal population and patients receiving transplants is another potential area of further study. Treatment states of hemodialysis, peritoneal dialysis and transplant can be explored further given the possible selectivity of the subcategories of mode of therapy for patients and confounding variables implicated.
There would be value in investigating further the 3 groups of patients on renal replacement therapy with controls, and comparison of data from other countries.

\section{Policy Implication}

This study should guide policies to improve the quality of life of persons on renal replacement therapy. Prevention of chronic kidney disease and other lifestyle diseases in this population should be a priority in healthcare. A fistula first effort for all patients on hemodialysis should be the gold standard and early fistula or graft protocols in all centres should be implemented. With $33 \%$ of patients on haemodialysis having an $\mathrm{AVF} / \mathrm{G}$, more fistula programmes are being established in the public sector currently so that this critical service is provided. In addition, initiatives for facilitating fistulas in rural centres can also be improved. The training and recruitment of specialists in this field is another potential enterprise that will reduce waiting times among haemodialysis patients.

Improved psychosocial support networks for dialysis patients and educational programmes for patients and 
families when deciding the choice of renal replacement therapy should be introduced.

Hemodialysis centres require revision of protocols and strict adherence to guidelines to reduce catheter-related bloodstream infections. Auditing at dialysis centres with strict quality control can be increased to focus on the issues patients encounter. Performing quality of life assessments for patients on renal replacement therapy in all centres can be instituted to improve care and compare treatment with an aim to prolong survival. In other settings, patient reported outcome measurements using the Kidney Disease Quality of Life questionnaire among other questionnaires for internal quality improvement activities. $^{48}$

The institution of policies for patients to be commenced on peritoneal dialysis once they are eligible instead of hemodialysis would significantly improve the health and quality of life of these patients. Early identification of hemodialysis patients who are suitable for peritoneal dialysis can greatly contribute to better quality of life where a small percentage of patients on renal replacement therapy receive transplants. The transplantation unit in our setting is state funded and requires a nephrologist referral. Furthermore, the centre performs at most 2 live donor transplants per month. In this developing country, an enhanced renal transplantation and peritoneal dialysis service would improve health-related quality of life among patients with end stage renal disease.

Expansion of programmes for organ donation and training of health care professionals in procurement can greatly assist the renal transplantation service. Targeting lifestyle diseases in our setting is also an invaluable measure in preventing progression to end-stage renal disease and the number of patients on hemodialysis.

\section{Contributions to Literature}

There are entities specific to a patient population that influences quality of life..$^{7,8,13,24}$ The diversity of elements affecting patients' health status on renal replacement has all contributed uniquely to research around the world throughout the years. Even in instances where transplantation provides a good quality of life, studies have shown other societal factors among this subcategory that significantly contribute to better scores. ${ }^{7,8,10}$

An article from 1995 comparing data reported from registries on renal replacement therapy around the world showed that the quantity and quality of renal replacement therapy is variable and depends to a considerable extent on the different political and socioeconomic background with the consequent differences in the health care systems existing in the various countries. ${ }^{49}$

In a study based at Walsgrave National Health Service Trust Hospital, on ethnicity influencing the perceived quality of life of patients on dialysis and following renal transplant, it was found that Asians had a lower quality of life when compared to White Europeans. ${ }^{24}$ In Brazil, unmarried and male patients presented better physical quality of life scores and among transplant recipients, the transplantation centre influenced quality of life. ${ }^{8}$ Other research has shown that the introduction of home dialysis, erythropoietin and vitamin D made the quality of life of dialysis patients comparable to kidney transplant recipients. ${ }^{50}$

This study shows that biological factors like comorbidities and socioeconomic influences affect a patient's quality of life. Peritoneal dialysis is an alternative option to transplantation in our resource-limited setting as it still provides a good quality of life for patients. Many hemodialysis patients in our population utilize permanent catheters. It is seen that there is a great struggle with achieving acceptable quality of life scores among hemodialysis patients in Trinidad and Tobago despite state funding for the majority among this subgroup.

\section{Conclusions}

In small island states and lower resource environments in larger countries where provision of assets is a continuously moving target, data generated in this research can be influential in policy determination across Latin America and the Caribbean as well as island states across the globe. This study on the quality of life and health state is the first in the Caribbean for patients on renal replacement therapy and has contributed novel West Indian data to the existing literature. With quality of life and state of health being invaluable measures of treatment outcome and the greater need for life-saving therapy for patients diagnosed with end-stage renal disease, this research should impact the allocation of resources for chronic kidney disease patients. More importantly, it should influence the prevention and management of lifestyle diseases in this population.

\section{Abbreviations}

ANOVA, analysis of variance; AVF, arteriovenous fistula; AVG, arteriovenous graft; $\mathrm{AVF} / \mathrm{G}$, arteriovenous fistula/ graft; BMI, body mass index; CI, confidence Interval; ERHA, Eastern Regional Health Authority; HD, 
hemodialysis; NCRHA, North Central Regional Health Authority; NWRHA, North West Regional Health Authority; PD, peritoneal dialysis; SE, standard error; SPSS, Statistical Package for the Social Sciences programme; STATA, Statistics and Data programme; SWRHA, South West Regional Health Authority; T, transplant; TRHA, Tobago Regional Health Authority; TT, Trinidad and Tobago.

\section{Data Sharing Statement}

The datasets used and/or analysed during the current study are available from the corresponding author on reasonable request. Most data generated or analysed during this study are included in this published article and its supplementary information files.

\section{Ethics Approval and Informed Consent}

Informed consent-written consent to collect and use information was obtained from all participants in this study. The University of the West Indies Ethics Committee approved the form used to acquire the written consent.

The University of the West Indies Faculty of Medical Sciences Campus Ethics Committee

Approval: CEC007/09/15

South West Regional Health Authority Office of the Director of Health Research Committee

North West Regional Health Authority Ethics Committee Eastern Regional Health Authority Research Committee Tobago Regional Health Authority Research Committee

This study was conducted in accordance with the Declaration of Helsinki.

The source of the donated organs was from live and deceased donors. All organs were donated voluntarily with written informed consent. This was conducted in accordance with the Declaration of Istanbul.

\section{Consent for Publication}

The corresponding author, S. Sanchez, created Figure 1. All components of the map of Trinidad and Tobago: demarcations, texts, colours, labels and symbols were created with Microsoft Paint 3D, 2016. The key was created with Microsoft Word 2016.

\section{Author Contributions}

Study design: SS, ST, RA, HB and GL. Data acquisition and interpretation: SS, GL, HB, ST and RA. Data analysis and statistical analysis: GL, HB, RA, ST and SS. Supervision: ST and HB. All authors have full access to the data in this study. HB and ST had final responsibility for the decision to submit the publication. Each author contributed intellectually to this study during drafting, revision and final version and all fully accept accountability for the work in this research. The STROBE (Strengthening the Reporting of OBservational Studies in Epidemiology) checklist for cross-sectional studies, supple mentary Table 2, is attached for this paper. All authors made substantial contributions to conception and design, acquisition of data or analysis and interpretation of data; took part in drafting the article or revising it critically for important intellectual content; agreed to submit it to the current journal; gave final approval for the version to be published; and agreed to be accountable for all aspects of the work.

\section{Funding}

This research did not receive any specific grant from funding agencies in the public, commercial, or not-forprofit sectors.

\section{Disclosure}

The authors report no conflicts of interest in this work.

\section{References}

1. Liem YS, Bosch JL, Arends LR. Quality of life assessed with the medical outcomes study short-form 36-Item health survey of patients on renal replacement therapy: a systematic review and metaanalysis. Value Health. 2007;10(5):390-397. doi:10.1111/ j.1524-4733.2007.00193.x

2. Cameron JI, Whiteside C, Katz J, Devins GM. Differences in quality of life across renal replacement therapies: a meta-analytic comparison. Am J Kidney Dis. 2000;35(4):629-637. doi:10.1016/S0272-6386(00) 70009-6

3. Makkar V, Kumar M, Mahajan R, Khaira NS. Comparison of outcomes and quality of life between hemodialysis and peritoneal dialysis patients in Indian ESRD population. J Clin Diag Res. 2015;9:28-31.

4. Mendes de Abreu M, Walker DR, Sesso RC, Ferraz MB. Healthrelated quality of life of patients receiving hemodialysis and peritoneal dialysis in São Paulo, Brazil: a longitudinal study. Value Health. 2011;13:191-211.

5. García-Llana H, Remor E, Selgas R. Adherence to treatment, emotional state and quality of life in patients with end-stage renal disease undergoing dialysis. Psicothema. 2013;25(1):79-86. doi:10.7334/ psicothema2012.96

6. Bakewell AB, Higgins RM, Edmunds ME. Quality of life in peritoneal dialysis patients: decline over time and association with clinical outcomes. Kidney Int. 2002;61(1):239-248. doi:10.1046/j.15231755.2002.00096.x

7. Fiebiger W, Mitterbauer C, Oberbauer R. Health-related quality of life outcomes after kidney transplantation. Health Qual Life Outcomes. 2004;2(1):2. doi:10.1186/1477-7525-2-2 
8. Alvares J, Cesar CC, Acurcio Fde A, Andrade EI, Cherchiglia ML. Quality of life of patients on renal replacement therapy in Brazil: comparison of treatment modalities. Qual Life Res. 2012;21(6):983991. doi:10.1007/s11136-011-0013-6

9. Laupacis A, Keown P, Pus N, et al. A study of the quality of life and cost utility of renal transplantation. Kidney Int. 1996;50(1):235-242. doi:10.1038/ki.1996.307

10. Oliveira de Mendonça AE, Torres G, Salvetti M, Alchieri JC, Costa IKF. Changes in quality of life after kidney transplantation and related factors. Acta Paul Enferm. 2014;27:287-292.

11. Eduardo N, Rodrigues R, Barata C. Dyadic relationship and quality of life of patients with chronic kidney disease. J Bras Nefrol. 2015;37 (3):315-322. doi:10.5935/0101-2800.20150051

12. Liem YS, Bosch JL, Hunink MG. Preference based quality of life of patients on renal replacement therapy: a systematic review and metaanalysis. Value Health. 2008;11(4):733-741. doi:10.1111/j.15244733.2007.00308.x

13. Panagopoulou A, Hardalias A, Berati S, Fourtounas C. Psychosocial issues and quality of life in patients on renal replacement therapy. Saudi J Kidney Dis Transpl. 2009;20(2):212-218.

14. Valderrabano F, Jofre R, Lopez-Gomez JM. Quality of life in end stage renal disease patients. Am J Kidney Dis. 2001;38(3):443-464. doi:10.1053/ajkd.2001.26824

15. Sayin A, Mutluay R, Sindel S. Quality of life in hemodialysis, peritoneal dialysis and transplantation patients. Transplant Proc. 2007;39(10):3047-3053. doi:10.1016/j.transproceed.2007.09.030

16. Khan S, Bisnath R, Jaipaul $J$ et al. Screening for chronic kidney disease in east Trinidad using the national kidney foundation guidelines; 2015 .

17. Soyibo AK, Barton EN. Report from the Caribbean renal registry. West Indian Med J. 2007;56(3):355. doi:10.1590/S004331442007000300025

18. Roberts L, Ramsaroop K, Seemungal T. Survival outcomes in renal transplantation in Trinidad and Tobago: SORTTT study. West Indian Med J. 2012;61(4):422-428. doi:10.7727/wimj.2012.201

19. International Standard Classification of Occupations of the United Nations. ISCO 08; 2010. Available from: www.ilo.org/public/english/ bureau/stat/isco. Accessed November 16, 2019.

20. World Health Organization. Global Database on body mass index: an interactive surveillance tool for monitoring nutrition transition; 2008. Available from: who.int/bmi/index. Accessed November 16, 2019.

21. World Health Organization. International classification of diseases and related health problems. ICD 10; 2016. Available from: www.who.int/ classifications/icd/ICD10Volume2, Version2016. Accessed July 16, 2019.

22. Tillin T, Sattar N, Godsland IF, Hughes AD, Chaturvedi N, Forouhi NG. Ethnicity specific obesity cut-points in the development of type 2 diabetes mellitus-a prospective study including three ethnic groups in the United Kingdom. Diabetic Med. 2015;32(2):226-234. doi:10.1111/dme.12576

23. Charlson ME, Pompei P, Ales KL, MacKenzie CR. A new method of classifying prognostic comorbidity in longitudinal studies: development and validation. $J$ Chronic Dis. 1987;40(5):373-383. doi:10.1016/0021-9681(87)90171-8

24. Bakewell AB, Higgins RM, Edmunds ME. Does ethnicity influence perceived quality of life of patients on dialysis and following renal transplant? Nephrol Dial Transplant. 2001;16(7):1395-1401. doi:10.1093/ndt/16.7.1395

25. Yee Chow SK, Ling Tam BM. Is the kidney disease quality of life-36 (Kidney Disease Quality of Life questionnaire-36) a valid instrument for Chinese dialysis patients? BMC Nephrol. 2014;15(1):199. doi:10.1186/1471-2369-15-199

26. Chen JY, Choi EPH, Wan EYF, et al. Validation of the disease specific components of the Kidney Disease Quality of Life-36(KDQOL 36) in Chinese dialysis patients undergoing maintenance dialysis. PLoS One. 2016;11(5):e0155188. doi:10.1371/journal. pone. 0155188
27. Ricardo AC, Hacker E, Lora CM, et al. Validation of the kidney disease quality of life-36 short form 36 (Kidney Disease Quality of Life questionnaire-36) US Spanish and English versions in a cohort of hispanics with chronic kidney disease. Ethn Dis. 2013;23(2):202_209.

28. Kurella M, Luan J, Yaffe K, Chertow GM. Validation of the kidney disease quality of life (Kidney Disease Quality of Life questionnaire) cognitive function subscale. Kidney Int. 2004;66(6):2361-2367. doi:10.1111/j.1523-1755.2004.66024.x

29. Bailey H, Stolk E, Kind P. Toward explicit prioritization for the Caribbean: an EQ-5D value set for Trinidad and Tobago. Value Health. 2016;11:60-67. doi:10.1016/j.vhri.2016.07.010

30. Wilson B, Cleary PD. Linking clinical variables with health related quality of life. JAMA. 1995;273(1):59-64. doi:10.1001/ jama.1995.03520250075037

31. Robinson BM, Akizawa T, Jager KI, Kerr PG, Saran R, Pisoni RL. Factors affecting outcomes in patients reaching end stage kidney disease worldwide: differences in access to renal replacement therapy, modality use, and hemodialysis practices. Lancet. 2016;388(10041):294-306. doi:10.1016/S0140-6736(16)30448-2

32. Evans RW, Manninen L, Garrison LP, et al. The quality of life of patients with end stage renal disease. $N$ Engl J Med. 1985;312 (9):553-559. doi:10.1056/NEJM198502283120905

33. Rabbat CG, Thorpe KE, Russell JD, Churchill DN. Comparison of mortality risk for dialysis patients and cadaveric first renal transplant recipients in Ontario, Canada. Clin J Am Soc Nephrol. 2000;11:59175922.

34. Don YK, Tammy KC, Myoung-Hee K, et al. Superior outcomes of kidney transplantation compared with dialysis: an optimal matched analysis of a national population-based cohort study between 2005 and 2008 in Korea. Medicine. 2016;95(33):4352. doi:10.1097/ MD. 0000000000004352

35. Ishiwatari A, Yamamoto S, Fukuma S, et al. Changes in quality of life in older hemodialysis patients: a cohort study on dialysis outcomes and practice patterns. Am J Nephrol. 2020;51(8):650-658. doi:10.1159/000509309

36. Francisco ALM, Fresnedo GF, Palomar R, Pinera C, Arias M. The renal benefit of a healthy lifestyle. Kidney Int. 2005;69:5256.

37. Chen MC, Tsai WL, Tsai IC, et al. Arteriovenous fistula and graft evaluation in hemodialysis patients using MDCT: a primer. $A m J$ Roentgenol. 2010;194(3):838-847. doi:10.2214/AJR.09.3357

38. Wasse H, Kutner N, Zhang R, Huang Y. Association of initial HD vascular access with patient reported health status and quality of life. Clin J Am Soc Nephrol. 2007;2(4):708-771. doi:10.2215/ CJN.00170107

39. Mohamed-Ali V, Goodrick S, Bulmer K, Holly JM, Yudkin JS, Coppack SW. Production of soluble tumor necrosis factor receptors by human subcutaneous adipose tissue in vivo. Am J Physiol. 1999;277:971-975.

40. Demas GE, Drazen DL, Nelson RJ. Reductions in total body fat decrease humoral immunity. Proc Royal Soc B. 2003;270 (1518):905-911. doi:10.1098/rspb.2003.2341

41. Beddhu S. The body mass index paradox and an obesity, inflammation, and atherosclerosis syndrome in chronic kidney disease. Semin Dial. 2004;17(3):229-232. doi:10.1111/j.0894-0959.2004.17311.x

42. Kalantar-Zadeh K, Abbott KC, Salahudeen AK, Kilpatrick RD, Horwich TB. Survival advantages of obesity in dialysis patients. Am J Clin Nutr. 2005;81(3):543-554. doi:10.1093/ajen/81.3.543

43. Ikizler TA. Resolved: being fat is good for dialysis patients: the Godzilla Effect. J Am Soc Nephrol. 2008;19(6):1059-1064. doi:10.1681/ASN.2007090983

44. Gerasimoula K, Lefkothea L, Maria L, Victoria A, Paraskevc T, Maria P. Quality of life in hemodialysis patients. Mater Sociomed. 2005;27(5):305-309. doi:10.5455/msm.2015.27.305-309 
45. McHorney CA, Tarlov AR. Individual-patient monitoring in clinical practice: are available health status surveys adequate. Qual Life Res. 1995;4(4):293-307. doi:10.1007/BF015938827

46. Chisholm-Burns MA, Erickson SR, Spivey CA, Gruessner RWG, Kaplan B. Concurrent validity of kidney transplant questionnaire in US renal transplant recipients. Patient Prefer Adherence. 2011;5:517-522. doi:10.2147/PPA.S24261

47. Lindsay RM, Heindenheim PA, Nesrahallah G, Garg AX, Suri R. Minutes to recovery after a hemodialysis session: a simple healthrelated quality of life question that is reliable, valid and sensitive to change. Clin J Am Soc Nephrol. 2006;1(5):952-959. doi:10.2215/ CJN.00040106
48. Peipert JD, Hays RD. Using patient reported measures in dialysis clinics. Clin J Am Soc Nephrol. 2017;12(11):1889-1891. doi:10.2215/CJN.02250217

49. Amico GD. Comparability of the different registries on renal replacement therapy. Am J Kidney Dis. 1995;25(1):113-118. doi:10.1016/ 0272-6386(95)90637-1

50. Milovanov YS, Dobrosmyslov IA, Milovanova SY, et al. Quality of life of chronic kidney disease patients on renal replacement therapy. Ter Arkh. 2018;90(6):89-91. doi:10.26442/terarkh201890689-91

\section{Publish your work in this journal}

The International Journal of Nephrology and Renovascular Disease is an international, peer-reviewed open-access journal focusing on the pathophysiology of the kidney and vascular supply. Epidemiology, screening, diagnosis, and treatment interventions are covered as well as basic science, biochemical and immunological studies. The manuscript management system is completely online and includes a very quick and fair peer-review system, which is all easy to use. Visit http://www.dovepress.com/testimonials.php to read real quotes from published authors. 